Post-print of (paper) J. Org. Chem., 2009, 74, 9071-9071.

\title{
One-Pot Synthesis of Polycyclic Nucleosides with Unusual Molecular Skeletons
}

Bonache, Maria-Cruz; Cordeiro, Alessandra; Carrero, Paula; Quesada, Ernesto; Camarasa, $M^{a}$ Jose; Jimeno, M. Luisa; San-Félix, Ana

Received September 4, 2009

DOI: 10.1021/jo9019144

María-Cruz Bonache, ${ }^{a}$ Alessandra Cordeiro, ${ }^{a}$ Ernesto Quesada, ${ }^{a}$ Paula Carrero, ${ }^{a}$ María-José Camarasa, ${ }^{a}$ María Luisa Jimeno ${ }^{b}$ and Ana San-Félix ${ }^{* a}$

anstituto de Química Médica (CSIC), Juan de la Cierva 3, 28006 Madrid.

bCentro de Química Orgánica "Lora-Tamayo" (C.S.I.C.), Juan de la Cierva, 3, Madrid

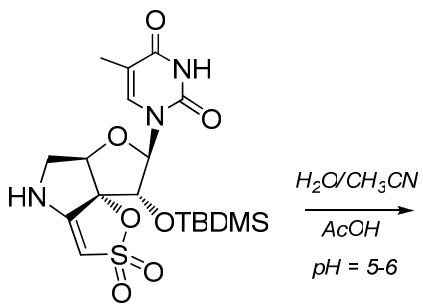

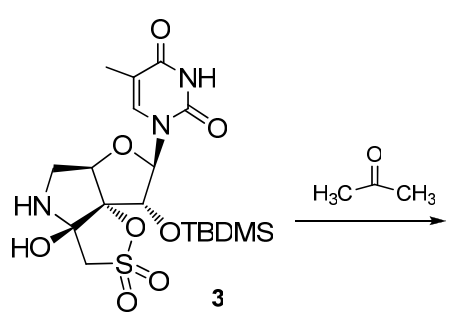

॥ึ 3
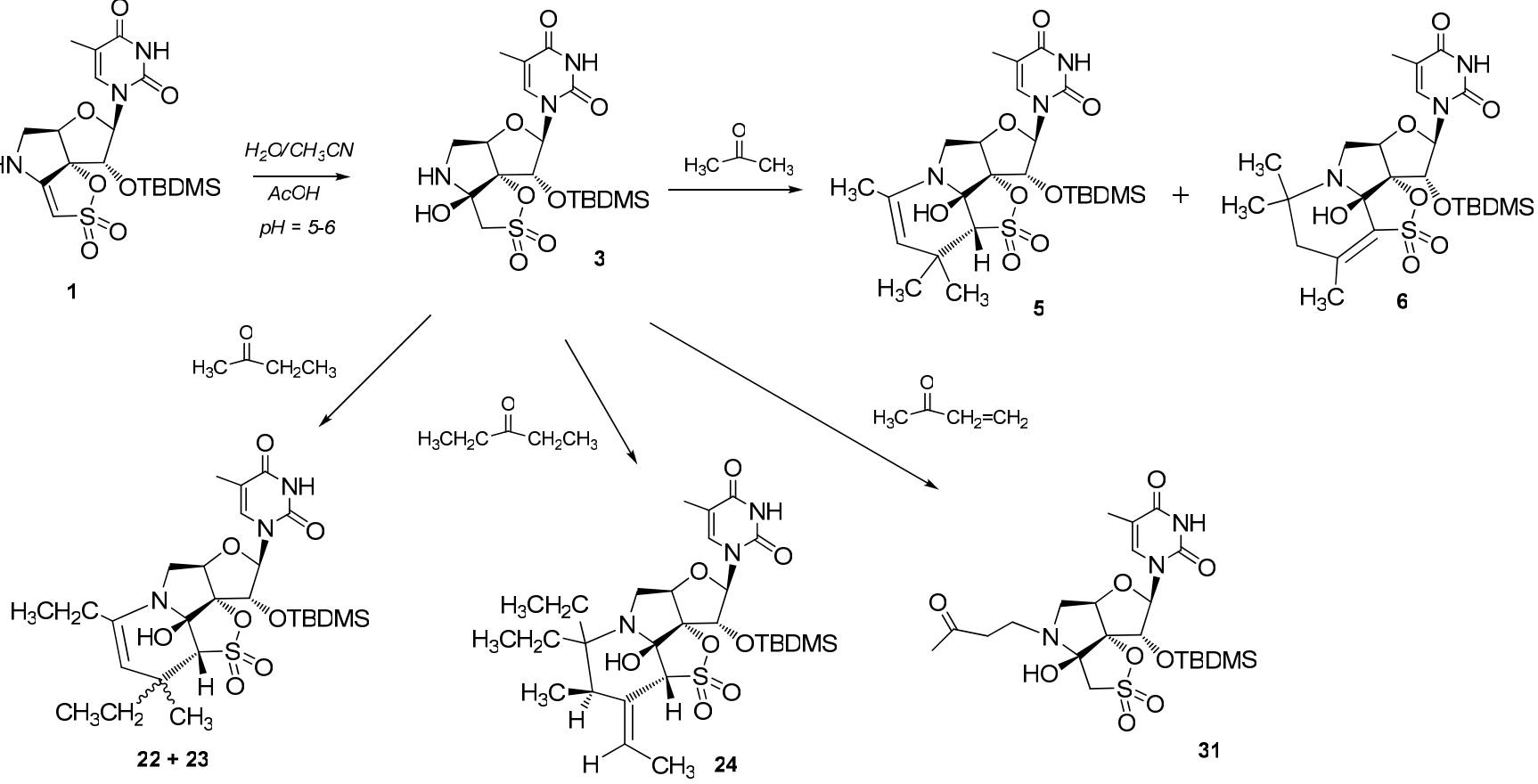
Reaction of enamine sultone $\mathbf{1}$ with a 1:1 mixture of water and acetonitrile in the presence of acetic acid $(\mathrm{pH}=5-6)$ allowed its efficient transformation into the hemiaminal $\mathbf{3}$. Unexpectedly, 3 underwent an spontaneous intermolecular reaction with acetone to give the novel tetracyclic nucleosides $\mathbf{5}$ and $\mathbf{6}$. The unique tetracyclic structure of $\mathbf{5}$ and $\mathbf{6}$ prompted us to start a study to explain their formation. A transient iminium intermediate, as result of the condensation of $\mathbf{3}$ with acetone, has been observed using NMR and HPLC-ESI-MS experiments. Additionally, through catalytic hydrogenation we were able to trap some of the putative iminium/enamine intermediates as the corresponding amines. The electrophilic nature of the iminium intermediate seems to be the driving force for the attack of a second molecule of acetone and for the subsequent intramolecular cyclizations that takes place to afford 5 and 6. It seems that the hydroxyl group at the $\alpha$-position of the pyrrolidine ring, present in $\mathbf{3}$, is also crucial for the formation of $\mathbf{5}$ and $\mathbf{6 .}$

The scope of the reaction was examined using simple aliphatic ketones (2-butanone, 3-pentanone), as well as the $\alpha, \beta$-unsaturated ketone (methyl vinyl ketone). Our experimental results indicate that the nature of the ketone $\left(\mathrm{R}^{1} \mathrm{COR}^{2}\right)$ is critical for the attack of the $\mathrm{NH}$ of the pyrrolidine ring present in $\mathbf{3}$ and the subsequent cyclization. Different types of ketones can be attacked by the $\mathrm{NH}$ of the pyrrolidine ring present in 3, however only with acetone the attack and subsequent cyclization proceeds spontaneously. 


\section{Introduction}

One of the challenges of the synthetic organic chemists is to discover novel and efficient reactions which allow the generation of structural, functional and stereochemical complex molecules in an efficient manner. The construction of multiple carbon-carbon bonds in a single chemical step represents a particularly efficient approach to achieve this goal. ${ }^{1,2}$

In two previous publications of our group it has been reported that the spirocyclic enamino sultone 1 (Scheme 1) is a versatile intermediate for the synthesis of a variety of highly functionalized polycyclic nucleosides having skeletal and stereochemical diversity. ${ }^{3,4}$ These compounds were efficiently obtained by a one-step reaction of the enamine sultone $\mathbf{1}$ with $O-, N-, S-, C$-nucleophiles and amino acids (Scheme 1$)^{4}$

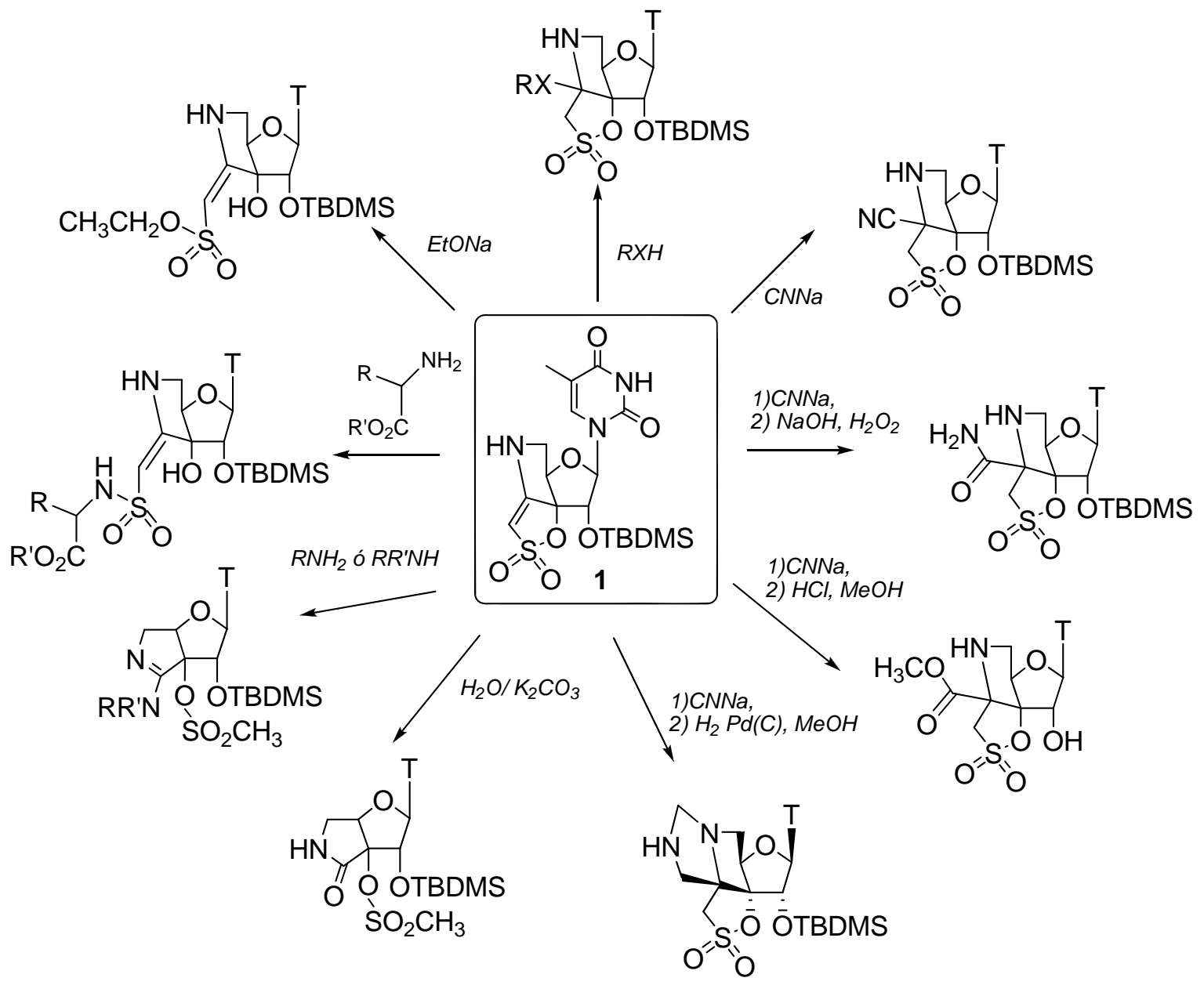


SCHEME 1. Reaction of enamine sultone 1 with $O$-, $N$-, $S$-, $C$-nucleophiles and amino acids

One of these transformations attracted powerfully our attention. That is the hydrolisis of the enamine sultone 1 under basic nonnucleophilic conditions (potassium carbonate) that afforded the bicyclic nucleoside 4 , in which a $\gamma$-lactam ring was fused to the ribose moiety (Scheme 2). ${ }^{4}$ This result was explained by a Michael-type addition of the nucleophile (water) to the conjugated double bond of the $\alpha, \beta$-unsaturated cyclic sulfonate ester in $\mathbf{1}$ to give intermediate 2 , which spontaneously tautomerizes to 3 . A subsequent opening of the spiroaminooxathioledioxide ring, due to the basic conditions used, was proposed to give 4 (Scheme 2).

\section{SCHEME 2. Proposed mechanism for the reaction of 1 with water}
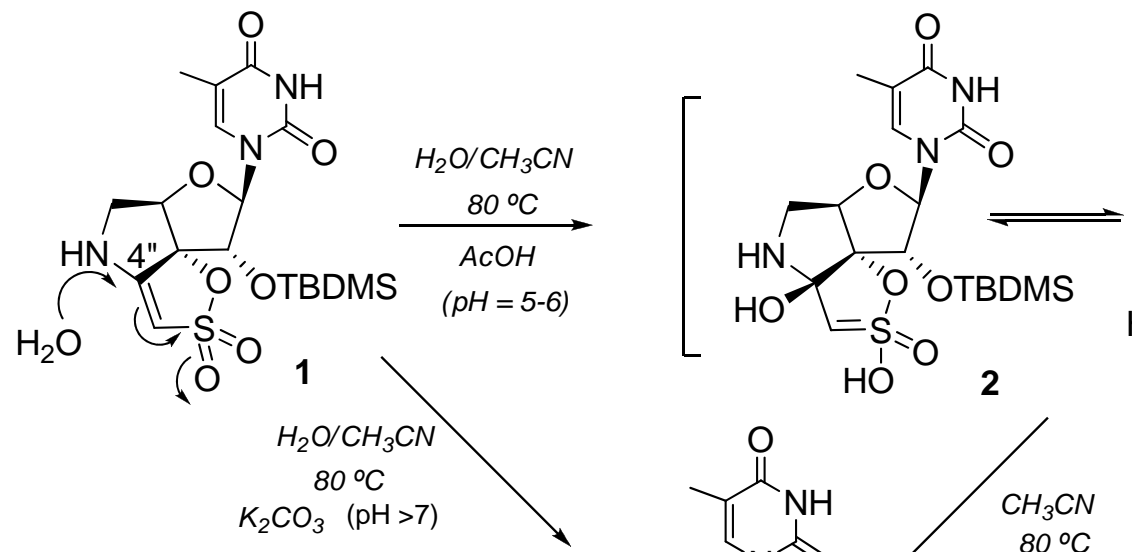

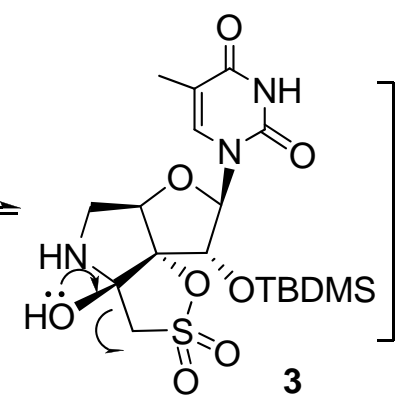

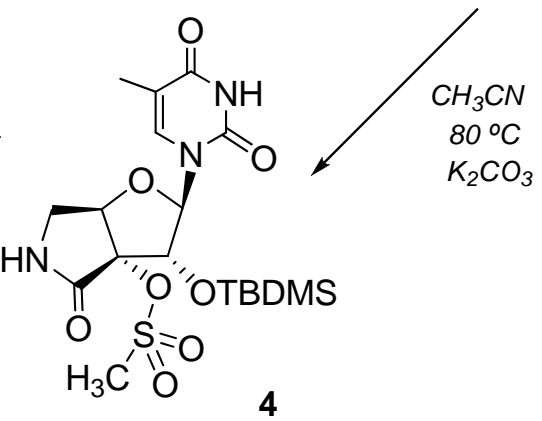


Although this mechanism satisfactorily explained the formation of 4 , no direct experimental verification for the existence of the postulated hydroxy tricyclic intermediates 2 and/or 3 was presented. The initial aim of this paper was to unequivocally intercept and characterize intermediates 2 and/or 3 to provide evidence for their participation in the

formation of 4. During the ${ }^{1} \mathrm{H}$ NMR studies carried out with such purpose we observed the spontaneous transformation of $\mathbf{3}$ into a mixture of compounds when acetone- $d_{6}$ was used as solvent. This unexpected finding provided the incentive for an extensive study aimed to elucidate the structure of the compounds formed in acetone and to explain the most probable way in which these compounds are formed.

\section{Results}

Chemistry. To identify conditions that might afford the proposed intermediates 2 and/or 3, the hydrolisis of the enamine sultone $\mathbf{1}$ (dissolved in a 1:1 mixture of water and acetonitrile) was studied in function of reaction time, temperature and $\mathrm{pH}$. The reaction was monitored using TLC. Among the sets of reaction conditions tested, the best results were found to be, weak acid media ( $\mathrm{pH}$ adjusted at 5-6 with acetic acid), $80^{\circ} \mathrm{C}$ and $8 \mathrm{~h}$ reaction time. Under these conditions, compound 3 was obtained in $93 \%$ yield. It should be emphasized that $\mathbf{3}$ was stable and could be efficiently isolated by centrifugal circular thinlayer chromatography (CCTLC).

Reaction of 3 with potassium carbonate $\left(0.1\right.$ eq) in acetonitrile at $80^{\circ} \mathrm{C}$ afforded the bicyclic nucleoside 4 in $80 \%$ yield (Scheme 1). This experimental result showed unambiguously that the isolated compound $\mathbf{3}$ is an intermediate in the formation of $\mathbf{4}$ and clearly supported the previously proposed mechanism. 
In the course of the ${ }^{1} \mathrm{H}$ NMR studies aimed to elucidate the structure of 3 , we observed an intriguing and unexpected behaviour when acetone- $d_{6}$ was used as the solvent. Only in this case, we observed that after $24 \mathrm{~h}$, nucleoside 3 was transformed into a mixture of compounds. NMR analysis of the crude reaction mixture was not obvious and we decided to repeat the reaction to isolate and characterize the compounds formed. Thus, a solution of $\mathbf{3}$ in dry acetone, was stirred at room temperature during $24 \mathrm{~h}$. Purification of the reaction mixture by CCTLC afforded two novel compounds, 5 and $\mathbf{6}$ in 35 and $30 \%$ yield, respectively (Scheme 3). When compound 3 was treated with an equimolar amount of acetone no transformation was observed. Amount of acetone was sequentially increased up to 20 equivalents and only in this case compounds $\mathbf{5}$ and $\mathbf{6}$ started to be formed (the reaction was followed by TLC) indicating that a large excess of acetone is needed to drive the reaction forward.

\section{SCHEME 3. Reaction of 3 with acetone}

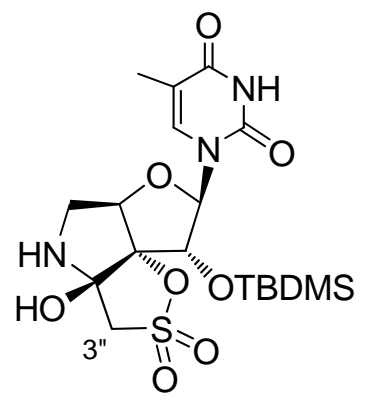

3

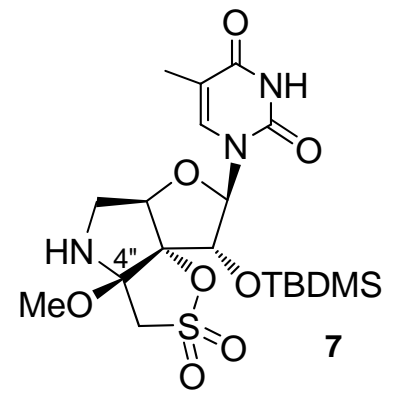

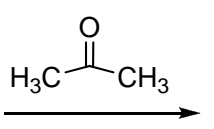

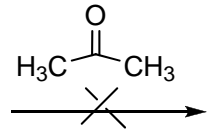

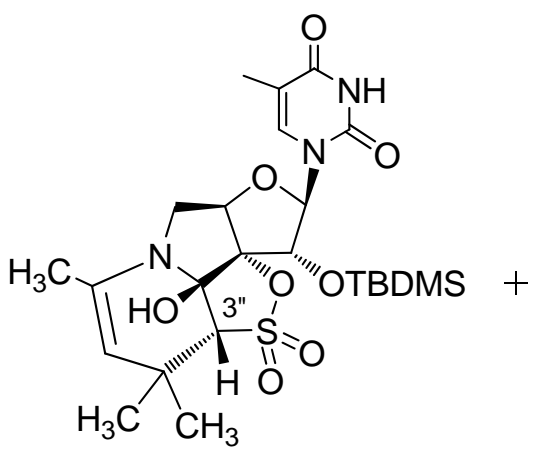

5 (35\%) (80\%) in the presence of acetic acid

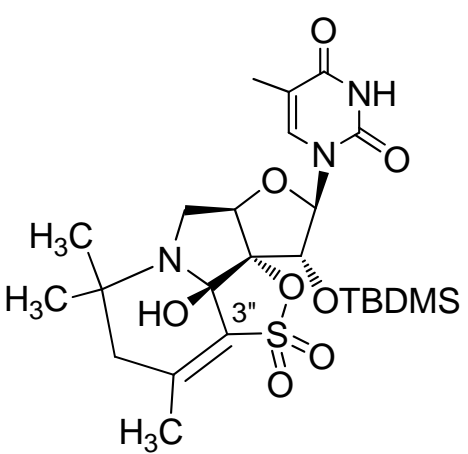

$6(30 \%)$

no reaction 
Structural assignments of $\mathbf{5}$ and $\mathbf{6}$. Assigment of the structures of nucleosides $\mathbf{5}$ and $\mathbf{6}$ was not obvious, and was achieved by ${ }^{1} \mathrm{H}$ and ${ }^{13} \mathrm{C}$ NMR, spectroscopy using mono-and bidimensional techniques ( $\mathrm{gHMBC}^{5}$ and $\left.\mathrm{gHSQC}^{6}\right)$.

With respect to 5 (Figure 1a), the ${ }^{1} \mathrm{H}$ NMR spectrum showed the disappearance of the characteristic $\mathrm{AB}$ system at $\sim \delta 3.60 \mathrm{ppm}$ present in the starting compound (3) and the appearance of five novel singlets: $\delta 1.35,1.36$ and $1.78 \mathrm{ppm}$ (integrating for three protons) and $\delta 3.45$, and $4.41 \mathrm{ppm}$ (integrating for one proton). The ${ }^{1} \mathrm{H}$-decoupled ${ }^{13} \mathrm{C}$ NMR spectrum of 5 showed 22 distinct resonances in agreement with the proposed structure.

a

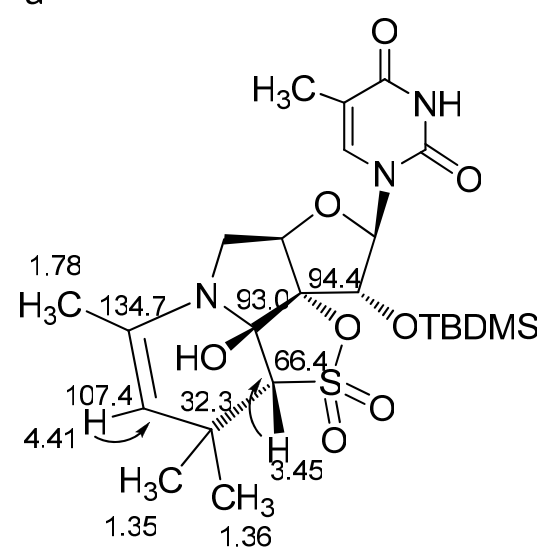

b

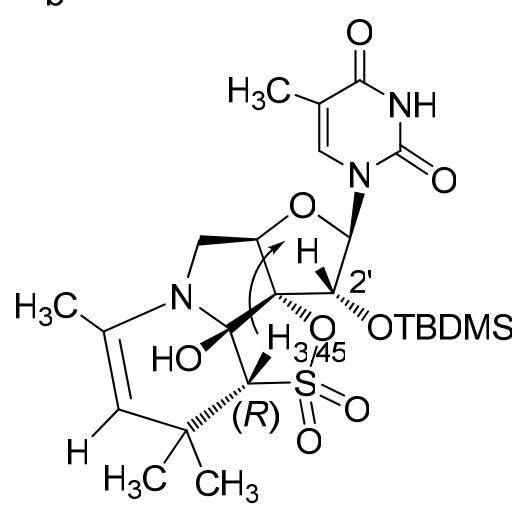

FIGURE 1. (a) Correlations observed from the gHSQC of compound 5. (b) Correlations observed from ROESY experiment of compound 5. Assignment of stereochemistry of $\mathbf{H}-3$ ",

The gHSQC spectrum showed the presence of four quaternary carbons $(\delta 32.3,93.0,94.4$ and $134.7 \mathrm{ppm})$. One of the most relevant information is that the signal at $\delta 107.4 \mathrm{ppm}$ (characteristic of a $\mathrm{sp}^{2}$ carbon) correlates with the novel singlet at $\delta 4.41$, so this signal might correspond to a vinylic proton. A correlation between the signal at $\delta 66.4 \mathrm{ppm}$ with the novel singlet at $\delta 3.45 \mathrm{ppm}$ was also observed. 
Crucial information came from the gHMBC analysis (Figure 2). In particular, the hypothetic vinylic proton at $\delta 4.41 \mathrm{ppm}$ showed long-range correlations with carbons at $\delta$ 134.7, $\delta 66.4$ and $32.3 \mathrm{ppm}$ and with the two methyl carbons that appeared at $\delta 26.1$ and $30.9 \mathrm{ppm}$ (Figure $2 \mathrm{a})$. On the other hand, $\mathrm{H}-5^{\prime}$ protons $(\delta 3.62,3.82 \mathrm{ppm})$ showed longrange correlations with the carbon at $\delta 134.7 \mathrm{ppm}$ indicating that this group is attached to the $\mathrm{NH}$ of the pyrrolidine ring of the starting material. Finally, the proton that appears at $\delta$ $3.45 \mathrm{ppm}$ showed correlations with carbons that belong to the novel fused ring: $\delta 107.4$, 32.3 and $30.9 \mathrm{ppm}$ and one quaternary carbon at $\delta 93.0 \mathrm{ppm}$ that belongs to the nucleosidic fragment (Figure 2b).
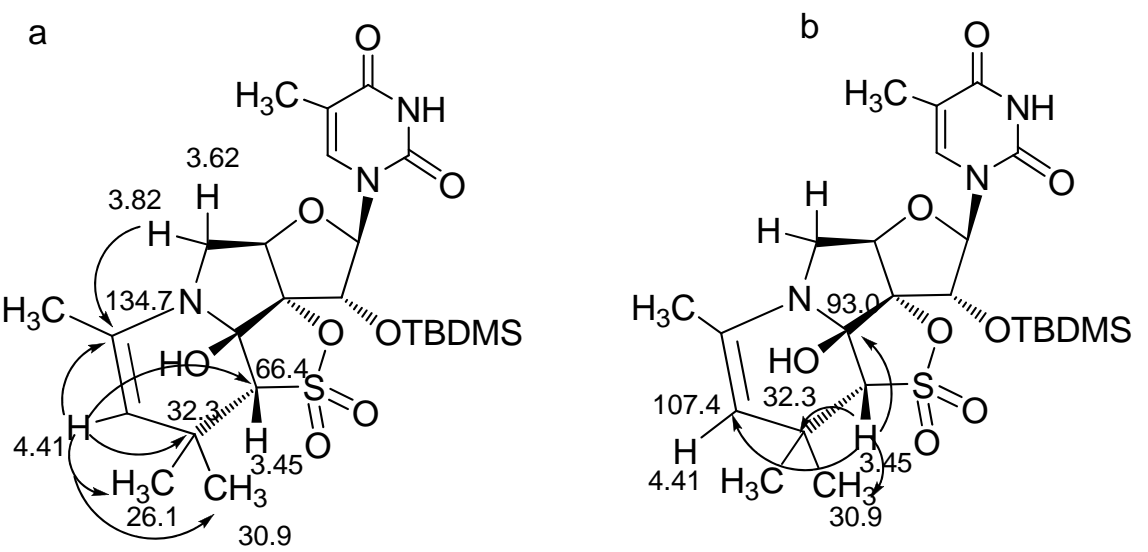

FIGURE 2. Observed correlations from the gHMBC spectrum of 5. (a) Correlations due to signal at $\delta 4.41 \mathrm{ppm}$. (b) Correlations observed for the signal at $\delta 3.45 \mathrm{ppm}$

The stereochemistry of the new stereogenic center created on C-3" was established as $R$ on the basis of a ROESY experiment (Figure 1b). Thus the signal at $\delta 3.45 \mathrm{ppm}$ has a correlation with the signal of the H-2' proton of the sugar indicating that these protons were at the same upper side of the furanose ring.

In the gHMBC experiment, compound 6 (Figure 3a) showed a long-range correlation between the H-5' protons ( $\delta 2.67$ and $3.29 \mathrm{ppm})$ and the quaternary carbon at $\delta 53.3 \mathrm{ppm}$ 
indicating that this carbon belongs to a new fragment that is attached to the $\mathrm{NH}$ of the pyrrolidine ring of the starting material. On the other hand, the presence of one $\mathrm{AB}$ system with signals at $\delta 2.34$ and 2.48 ppm, compatible with a $\mathrm{CH}_{2}$, was crucial for the identification of this compound. It was observed correlations between these $\mathrm{CH}_{2}$ protons with both the carbons of the novel fused ring that appears at: $\delta 19.3,29.0,31.4,53.3$ and $147.8 \mathrm{ppm}$ and the quaternary carbon at $\delta 126.7 \mathrm{ppm}$ that belongs to the nucleosidic fragment. Finally, the singlet that appears at $\delta 2.14 \mathrm{ppm}$ correlates with both the carbons of the novel fused ring that appears at: $\delta 40.0 \mathrm{ppm}$ and $147.8 \mathrm{ppm}$ and the quaternary carbon at $\delta 126.7 \mathrm{ppm}$ that belongs to the nucleosidic fragment (Figure $3 \mathrm{~b}$ ).
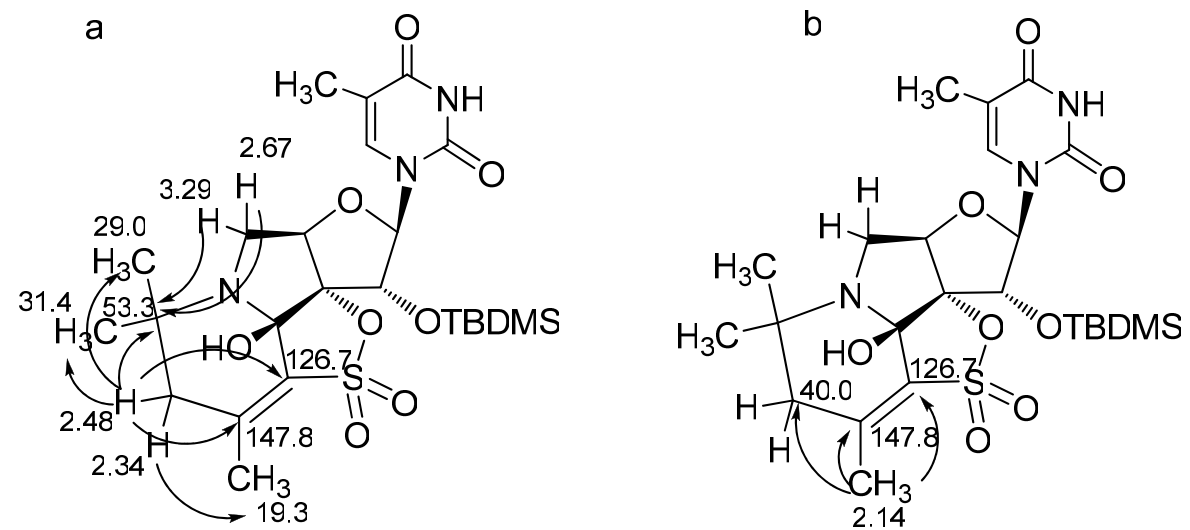

FIGURE 3. Observed correlations from gHMBC of 6. (a) Observed correlations due to signals at $\delta 2.34$ and $2.48 \mathrm{ppm}$. (b) Observed correlations due to signal at $\delta 2.14 \mathrm{ppm}$

Mechanistic considerations. The structure of nucleosides 5 and $\mathbf{6}$ indicated that $\mathbf{3}$ underwent an unexpected reaction with acetone in which two novel carbon-carbon bonds were formed to construct in a one-pot manner a novel six-membered ring in which the nitrogen and the carbon adjacent to the $\mathrm{OSO}_{2}$ of the original nucleoside 3 are ring atoms (Scheme 3). This novel ring contained a double bond and was fused to the original 
nucleoside $\mathbf{3}$ in two possible forms, one leads to $\mathbf{5}$ and the other to $\mathbf{6}$. The defined absolute stereochemistry of the new stereogenic center created on C-3" in compound 5 highlighted the complete stereoselectivity of the transformation.

Fascinated by the transformation that experiment $\mathbf{3}$ in acetone and the unique structure of nucleosides $\mathbf{5}$ and $\mathbf{6}$ we decided to study this reaction more in detail.

A plausible mechanism for the formation of $\mathbf{5}$ and $\mathbf{6}$ is illustrated in Schemes 4 and 5 respectively. We propose that the reaction could be initiated by the nucleophilic attack of the $\mathrm{NH}$ of the pyrrolidine ring, present in 3 , to the carbonyl moiety of the acetone to give the carbinolamine intermediate 8. This extremely easy attack is consistent with previously published results of our group evidencing the high reactivity of the $\mathrm{NH}$ of the pyrrolidine ring present in tricyclic nucleosides toward reagents that contain carbonyl groups. ${ }^{4}$ In addition, from Stork's work on the chemistry of enamines, it was known that pyrrolidines condenses very efficiently with ketones and other carbonyl compounds. ${ }^{7}$

\section{SCHEME 4. Proposed evolution of 3 towards 5 (enamine pathway)}




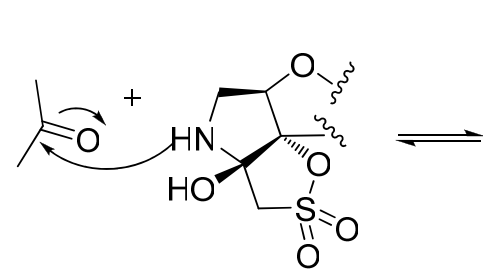

3

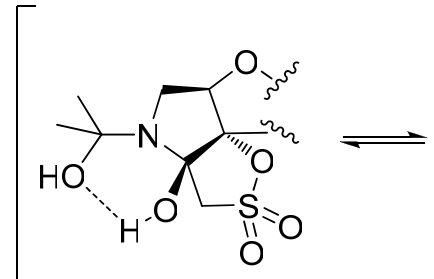

carbinolamine 8

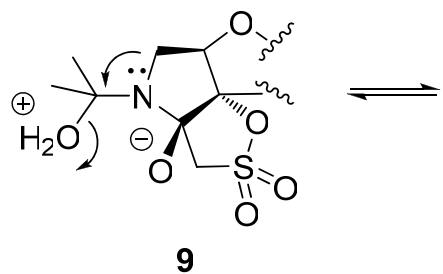

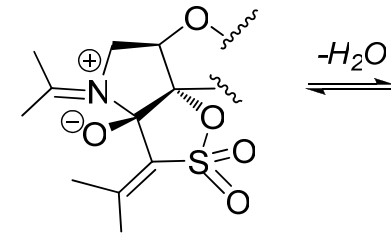

12

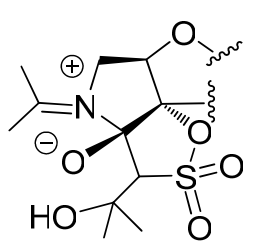

11

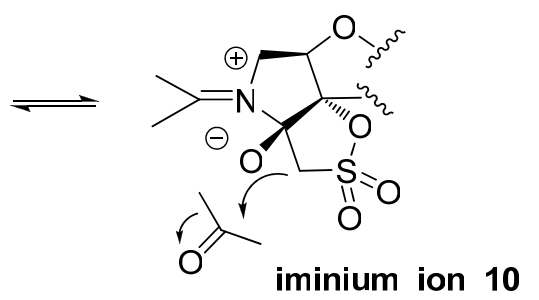

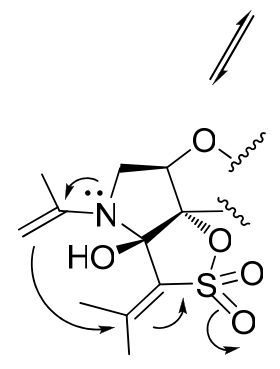

Enamine 13

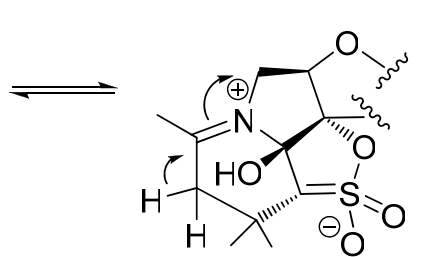

14

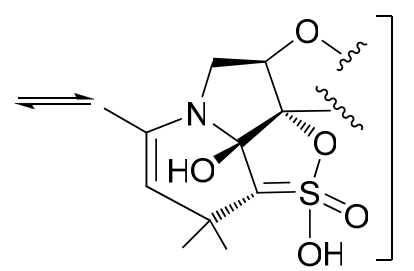

15

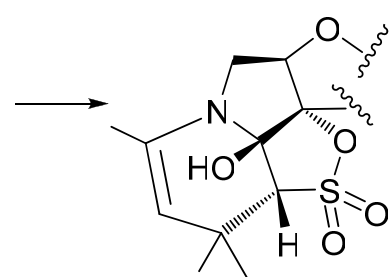

5

In the next step, a proton transfer mediated by the $\mathrm{OH}$ at the $\alpha$-position of the pyrrolidine ring may afford 9. A subsequent dehydratation step can take place to afford the iminium intermediate $\mathbf{1 0 .}$

It can be assumed that the hydrogen atoms (H-3") of the $\gamma$-sultone ring (adjacent to a strong electron-withdrawing moiety, $\mathrm{OSO}_{2}$ ) experiment an increase in $\mathrm{C}-\mathrm{H}$ acidity upon conversion of the $\mathrm{NH}$ of the pyrrolidine ring into an iminium ion. Thus, these $\mathrm{C}-\mathrm{H}$ acidic pro-nucleophile hydrogen atoms might react with a second molecule of acetone to afford 11, in which a novel carbon-carbon bond was formed. Dehydratation of 11, by elimination of the acidic proton adjacent to the $\mathrm{SO}_{2}$ might give the novel iminium intermediate 12 that 
might isomerize to afford enamine 13. Such isomerization might proceed through a proton transfer from one of the methyl groups attached to the nitrogen of the pyrrolidine ring to the oxygen $\left(\mathrm{O}^{-}\right)$at the $\alpha$-position of the pyrrolidine. Subsequently the conjugate addition of the enamine to the activated $\left(\mathrm{C}=\mathrm{C}-\mathrm{SO}_{2}\right)$ olefin located at the southern hemisphere of $\mathbf{1 3} \mathrm{might}$ give the iminium intermediate 14. A vast array of transformations via enamine intermediates, among them the conjugate addition to vinyl sulfones, has been reviewed by List et al. in $2007^{8}$ giving strong support for this reaction. Once formed, $14 \mathrm{might}$ experiment a proton transfer followed by isomerization to give $\mathbf{5}$.

The iminium ion intermediate $\mathbf{1 2}$ can follow an alternative pathway that leads to the formation of $\mathbf{6}$ (Scheme 5). The oxygen $\left(\mathrm{O}^{-}\right)$at the $\alpha$-position of the pyrrolidine ring might accept a proton from one of the neighbouring methyl groups attached to the southern hemisphere of the molecule to afford the iminium intermediate $\mathbf{1 6}$ that might be in equilibrium with 17. Subsequently, a concerted intramolecular cyclization, promoted by iminium catalysis might give 6 .

\section{SCHEME 5. Proposed evolution of 3 towards 6 (iminium pathway)}

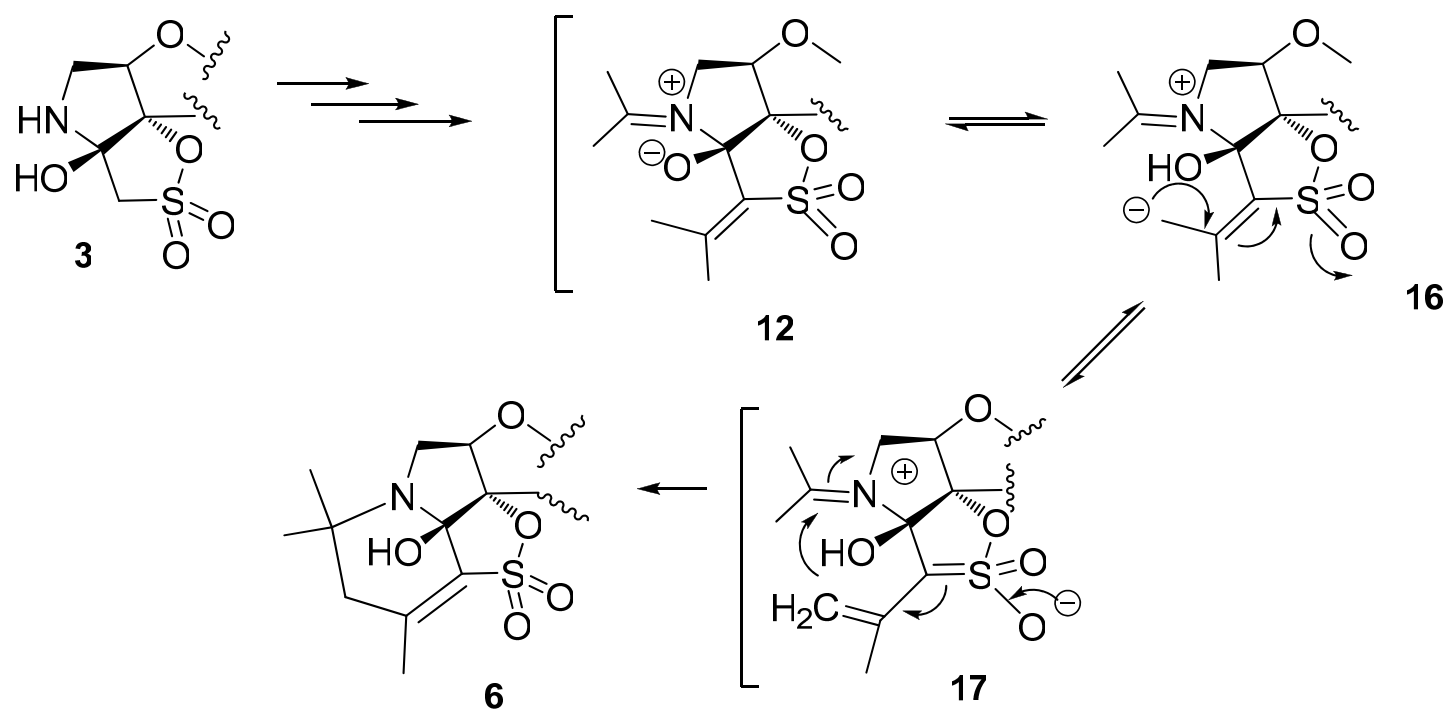


Participation of iminium/enamine intermediates in the intramolecular cyclizations that have been proposed to explain the formation of compounds $\mathbf{5}$ and $\mathbf{6}$ agrees with literature precedents evidencing that a vast array of transformations has been achieved via these type of intermediates. ${ }^{8-10}$ Among them, many important carbon-carbon forming reactions, including the Stork-enamine reaction, ${ }^{7}$ that involves the addition of an enamine to an $\alpha, \beta-$ unsaturated carbonyl acceptor, and the Mannich, ${ }^{10}$ Michael $^{11}$ and aldol ${ }^{12}$ reactions catalyzed by secondary amines, including $(S)$-proline and other proline-derived catalysts ${ }^{13}$ which in most cases involve a modification of the carboxylic acid functionality.

A remarkable aspect of our mechanistic proposal is that the various proton transfers that take place in the formation of $\mathbf{5}$ and $\mathbf{6}$ seem to be mediated by the hydroxyl functionality at the $\alpha$-position of the pyrrolidine ring, suggesting a critical role for this $\mathrm{OH}$. To check this hypothesis, the methoxy derivative 7 which has one OMe group at the $\alpha$-position of the pyrrolidine instead of the $\mathrm{OH}$ (Scheme 3), was reacted with acetone and no trace of any novel compound was detected. This result showed that the $\mathrm{OH}$ at the $\alpha$-position of the pyrrolidine ring is crucial for the progress of the reaction. A careful survey of the literature revealed that in those reactions that are either catalyzed by $(S)$-proline,${ }^{8-12}$ or other prolinederived catalysts, ${ }^{13}$ proton transfers have also been observed. As in our case, the crucial proton is always transferred from the functional group at the $\alpha$-position of the proline ring.

With the aim to provide support for the proposed mechanism, the transformation of $\mathbf{3}$ in acetone with a small amount of acetone- $d_{6}(10 \%)$ was monitored by spectroscopic ${ }^{1} \mathrm{H}$ and ${ }^{13} \mathrm{C}$ NMR at room temperature.

Figure 4 shows the portion of the ${ }^{1} \mathrm{H}$ NMR spectrum between $\delta 3.0$ and $7.7 \mathrm{ppm}$. The most significant difference between the starting and the final spectra was the disappearance of the characteristic $\mathrm{AB}$ system at $\sim \delta 3.60 \mathrm{ppm}$ that corresponds to the protons adjacent to the $\mathrm{OSO}_{2}$ in 3. Several novel species were detected since the first few minutes of the reaction 
(10-30 min), from them, species $\mathbf{X}$ (with a signal clearly observed at $\delta 7.5 \mathrm{ppm}$ ) is one of the most abundant. The concentration of $\mathbf{X}$ increased concomitant with decreasing $\mathbf{3}$. After $1 \mathrm{~h}$ $30 \mathrm{~min}, \mathbf{X}$ and $\mathbf{3}$ appeared in almost identical proportion and at this time a novel second species, subsequently identified as 6, started to appear. Almost all the starting material (3) was consumed in $7 \mathrm{~h}$ and at this time $\mathbf{X}$ together with a small amount of $\mathbf{6}$ can be detected. Since this moment the concentration of $\mathbf{X}$ decreased concomitant with increasing $\mathbf{6}$. After 4 days 6 was the only compound in solution. By contrast, we were unable to detect $\mathbf{X}$, indicating that it is an unstable intermediate (kinetic product) in the reaction.

Taking in consideration that after $7 \mathrm{~h}$ intermediate $\mathbf{X}$ is the most abundant in the reaction mixture (Figure 4), analysis of the spectroscopic data after this time might be very informative to elucidate its structure. The ${ }^{13} \mathrm{C}$ NMR spectrum showed an unusual signal at $\delta$ 191.2 ppm, compatible with the presence of an iminium carbon $\left(\mathrm{N}=\mathrm{C}^{+}\right)$that according to literature data ${ }^{13 \mathrm{a}}$ appears at $\delta 189.8 \mathrm{ppm}$. In the gHMBC experiment (supporting material), a long-range correlation between the $\mathrm{H}-5$, protons $(\delta 4.05 \mathrm{ppm})$ and the iminium carbon ( $\delta 191.2 \mathrm{ppm})$ was clearly observed. This result confirms that a condensation takes place between the pyrrolidine portion present in $\mathbf{3}$ and acetone to give an iminium intermediate at the northern hemisphere of the molecule. However, the NMR experiments do not provide information about the precise structure of $\mathbf{X}$ at the southern part of the molecule due to the partial deuteration of the methyl protons and their spectral overlap with the solvent signal. 

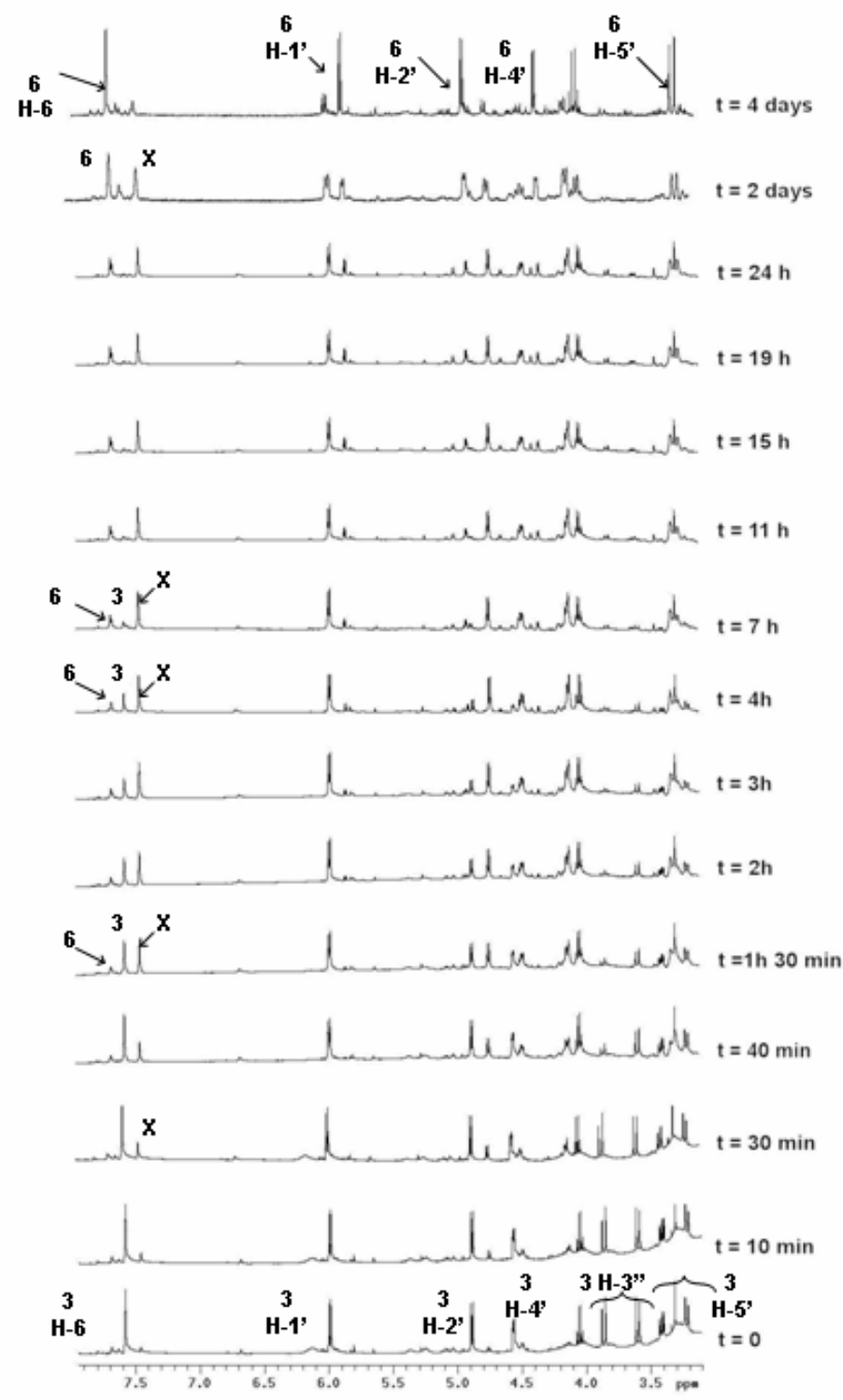

FIGURE 4. Evolution of the reaction of 3 in acetone monitored by ${ }^{1} \mathrm{H}-\mathrm{NMR}$ at different times (0-4 days).

We have also undertaken the analysis of the changes that experiment $\mathbf{3}$ in acetone by HPLC-ESI-MS (Figure 5). After $1 \mathrm{~h}$ the signal $\mathrm{m} / \mathrm{z} 475$, corresponding to the starting material 3 is clearly recognizable. There are also minor peaks $\mathrm{m} / \mathrm{z} 538$ and $\mathrm{m} / \mathrm{z} 574$ which can be assigned to the cationized iminium intermediate $\mathbf{1 0 .} \mathrm{Na}^{+}$and the protonated intermediate $\mathbf{1 1 . \mathbf { H } ^ { + }}$ respectively. It was possible to follow the reaction over time by 
monitoring the decrease of the intensity of the signal of 3 and the increase of that of $\mathbf{1 0 .} \mathbf{N a}^{+}$ and 11. $\mathbf{H}^{+}$After 7 hours the signals corresponding to the iminium intermediate $\mathbf{1 0 .} \mathbf{N a}^{+}(\mathrm{m} / \mathrm{z}$ 538) and intermediate $\mathbf{1 1 .} \mathbf{H}^{+}(\mathrm{m} / \mathrm{z} 574)$ are the most intensive peaks. There are also minor peaks, among them the corresponding to the starting material 3 and final compound $(6, \mathrm{~m} / \mathrm{z}$ $\left.556, t_{R}=13.21\right)$. After $24 \mathrm{~h}$ the signal of the starting material 3 appear in the chemical noise and the intensity of the signal of $\mathbf{1 0 .} \mathbf{N a}^{+}$and $\mathbf{1 1 . \mathbf { H } ^ { + }}$ started to decrease and those of $\mathbf{6}$ to increase. It should be noted that apart from peaks corresponding to compounds $\mathbf{3}$ and $\mathbf{6}$ or intermediates 10. $\mathrm{Na}^{+}$and $\mathbf{1 1 . \mathrm { H } ^ { + }}$ other peaks corresponding to unknown species were also detected. This observation seems to indicate that most of the reactions involved in the formation of $\mathbf{6}$ are equilibrium processes, consequently all intermediates are in principle present in the solution, and are detectable by HPLC-MS as protonated and/or cationized ions. This is in agreement with the fact that a large excess of acetone is needed to drive the reaction forward.

FIGURE 5. Evolution of the reaction of 3 in acetone monitored by HPLC-ESI-MS at different times (1-24 h).

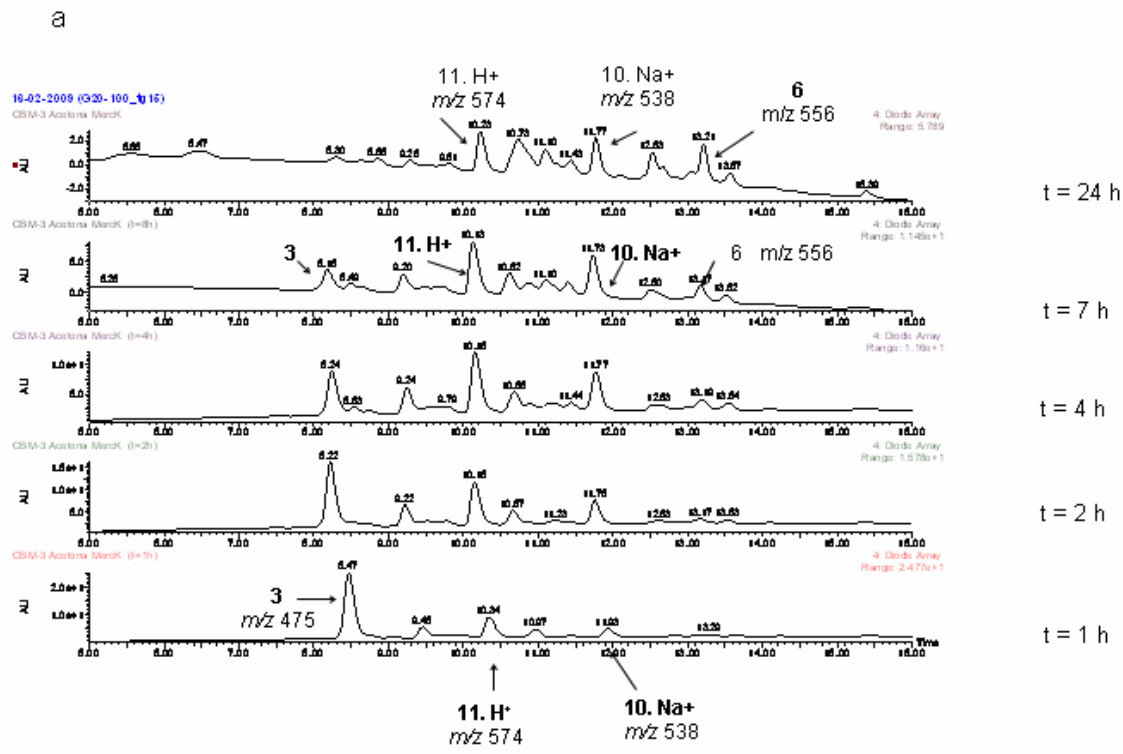


When acetone of HPLC grade (with a higher amount of water) was employed, the evolution of the starting material 3 towards intermediate $\mathbf{1 0 .} \mathbf{N a}^{+}(\mathrm{m} / \mathrm{z} 538)$ was clearly observed. However, we have not been able to detect the formation of $\mathbf{1 1 . \mathbf { H } ^ { + }}$ or the final compound 6 even after a prolonged reaction time (13 days). This finding seems to indicate that in presence of water the reaction stops in the first step and the reaction with a second molecule of acetone and the subsequent closing step do not take place.

It is worthy to note that only the formation of compound $\mathbf{6}$ can be detected by NMR and HPLC-ESI-MS in the reaction of 3 with acetone, however we have been unable to detect the formation of $\mathbf{5}$. Because 5 was only obtained after the purification process, we reasoned that the acidity of the silica gel used in the chromatography could play a critical role in its formation. To check that hypothesis the reaction of 3 with acetone was monitored by ${ }^{1} \mathrm{H}$ NMR in the presence of acetic acid (pH adjusted to 5-6). Under these conditions only formation of 5 was detected while compound $\mathbf{6}$ was not formed. In addition, the presence of acetic acid led to a significant decrease in the reaction time (4h versus 4 days).

Analysis of the changes that experiment 3 in acetone in the presence of acetic acid were also analyzed by HPLC-ESI-MS (Figure 6). As it was shown, a signal ( $\left.\mathrm{m} / \mathrm{z} 556, t_{R}=13.70\right)$ corresponding to the final product 5 (compound 6 appears at $t_{R}=13.21$ ) together with the signals, $\mathrm{m} / \mathrm{z} 538$ and $\mathrm{m} / \mathrm{z} 574$ corresponding to $\mathbf{1 0 .} \mathbf{N a}^{+}$and $\mathbf{1 1 . H ^ { + }}$, appeared after $4 \mathrm{~h}$. After $10 \mathrm{~h}$ the signal $(\mathrm{m} / \mathrm{z} 556)$ corresponding to the final product $\mathbf{5}$ is clearly dominant.

FIGURE 6. Evolution of the reaction of 3 in acetone in the presence of acetic acid (pH adjusted to 5-6) monitored by HPLC-ESI-MS 


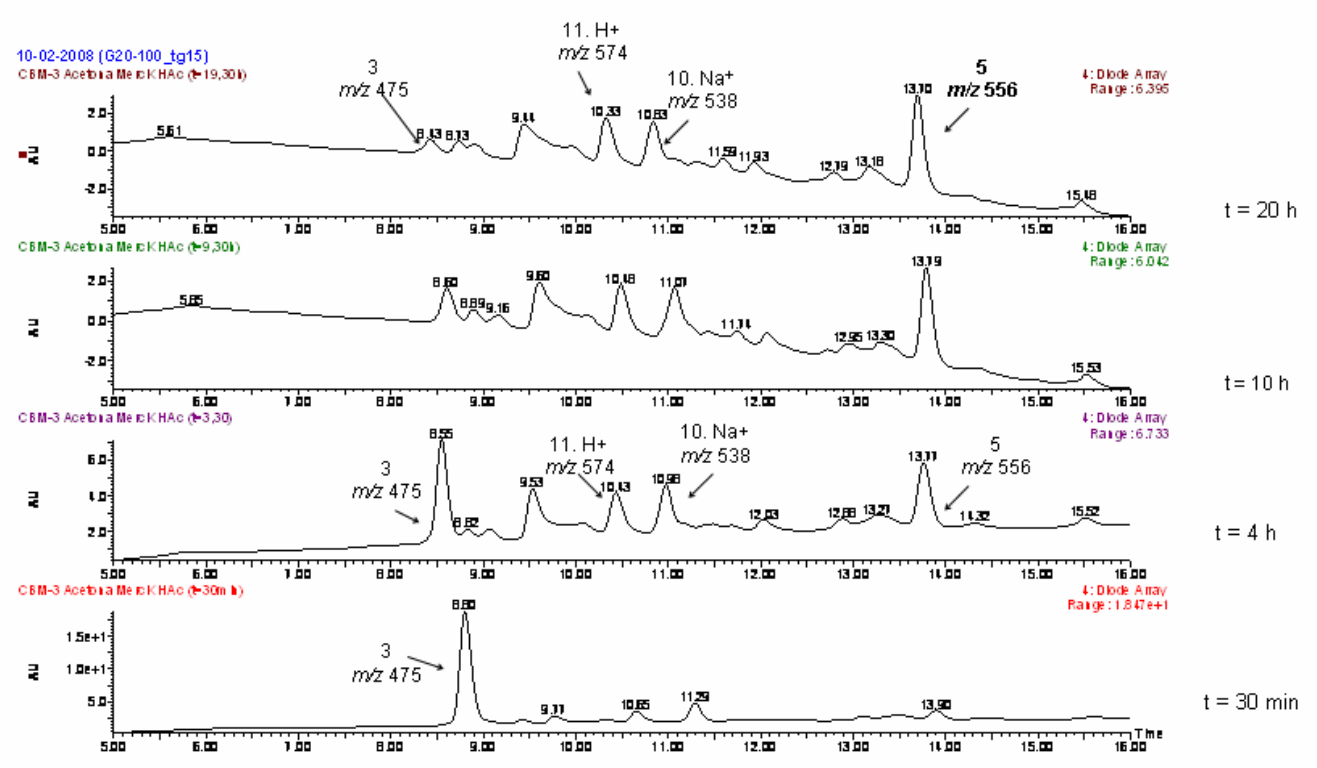

Taking in consideration that the formation of $\mathbf{5}$ and $\mathbf{6}$ follows enamine and iminium pathways respectively (Schemes 4 and 5) our results clearly indicate that the added acetic acid should facilitate the enamine pathway and therefore the formation of 5 (Scheme 4). The catalytic effect of an acid in the iminium-enamine equilibrium has been observed in other reported reactions. ${ }^{14}$

With these experimental findings in hand we decided to repeat the reaction of $\mathbf{3}$ with acetone in the presence of acetic acid (pH adjusted to 5-6). Under these conditions, the yield of 5 increased from $35 \%$ to $80 \%$ and only traces of compound 6 were detected (Scheme 3). 
Taken together, our NMR and HPLC-ESI-MS studies provided strong support for the participation of the iminium intermediates $\mathbf{1 0}$ and $\mathbf{1 1}$ in the formation of 5 and $\mathbf{6}$. Based on

our results the structure of intermediate $\mathbf{X}$, observed by ${ }^{1} \mathrm{HNMR}$, can be tentatively assigned as one of these intermediates or a mixture of close related intermediates with a rapid equilibration on the NMR timescale.

Finally, to reinforce the NMR and HPLC-ESI-MS studies we decided to perform hydrogenation experiments to trap some of the enamine and/or iminium intermediates proposed in the formation of $\mathbf{5}$ and $\mathbf{6}$. With this aim, a solution of $\mathbf{3}$ in acetone was stirred under $\mathrm{H}_{2}$ using palladium on carbon as catalysts (Scheme 6). Under these conditions compound 19 was isolated ( $80 \%$ yield) and no traces of 5 or $\mathbf{6}$ (or their corresponding hydrogenated derivatives) were detected. This result confirms that a condensation takes place between 3 and acetone since the first few minutes of the reaction to form the iminium intermediate 10. Hydrogenation of the $\mathrm{C}=\mathrm{N}$ double bond in 10, leads to the formation of an $N$-alkylated pyrrolidine 18. This result can be interpreted as evidence for the fact that the electrophilic nature of the iminium intermediate $\mathbf{1 0}$ should be the driving force for the attack of a second molecule of acetone at the southern hemisphere of the molecule. In absence of this second molecule of acetone, intermediate $\mathbf{2 0}$ experiments the spontaneous opening of the spiro sultone ring to afford 19. This reaction highlighted the tendency of the hydroxy group of the pyrrolidine ring to lose a proton, even under neutral conditions, and reinforces the crucial role assigned to this $\mathrm{OH}$ in the hydrogen transfers of our proposed mechanism.

\section{SCHEME 6. Reaction of 3 with acetone under hydrogenation conditions}




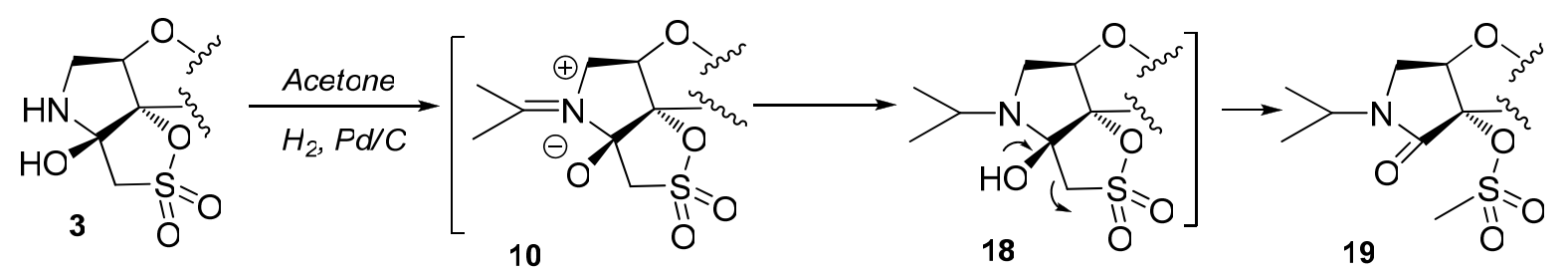

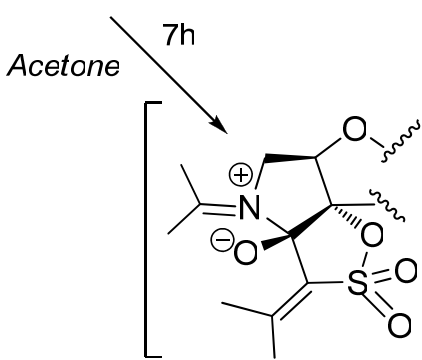

12

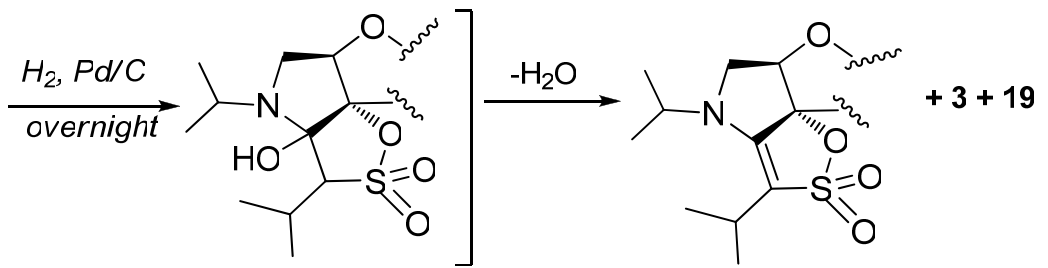

20
21

When a solution of $\mathbf{3}$ in acetone was stirred for $7 \mathrm{~h}$ and then hydrogenation in the presence of palladium on carbon was undertaken, a complex mixture of compounds were formed from which compounds $\mathbf{3}$ and $\mathbf{1 9}$ could be isolated in low yields. In addition, a novel compound (21) could be isolated in $30 \%$ yield (Scheme 6). Formation of $\mathbf{2 1}$ is an important experimental finding that gives strong support for the formation of intermediates in which two molecules of acetone at the northern and southern part of $\mathbf{3}$ are present. Taken into consideration that no acetic acid was used in the reaction, the formation of $\mathbf{2 1}$ can be explained through intermediates 12, 16 or 17 proposed in the iminium pathway (Scheme 5). Scheme 6 illustrates a possible pathway to 21 starting from 12, also intermediates 16 and 17 had given 21 under hydrogenation conditions. Simultaneous hydrogenation of the $\mathrm{C}=\mathrm{N}^{+}$and $\mathrm{C}=\mathrm{C}$ double bonds present in $\mathbf{1 2}$ might lead to the formation of the $N$-alkylated pyrrolidine 20 whose dehydratation might afford 21. It should be noted that under the conditions used $(\mathrm{Pd} / \mathrm{C})$ the intramolecular double bond present in $\mathbf{2 1}$ was not hydrogenated. This result is consistent with results of our group (unpublished data) evidencing that similar intramolecular double bonds were not hydrogenated under these conditions requiring more energetic conditions $\left(\mathrm{H}_{2} / \mathrm{PtO}_{2}\right)$. 
Formation of $\mathbf{2 1}$ can be interpreted as evidence for the fact that the electrophilic nature of the $\mathrm{C}=\mathrm{N}^{+}$is the driving force not only for the attack of a second molecule to the southern part of $\mathbf{3}$ but also for the intramolecular cyclizations that take place between the acetone fragments at the northern and southern hemispheres to afford 5 and $\mathbf{6}$.

The ${ }^{1} \mathrm{H}$ NMR spectrum of 21 showed the presence of two novel sextuplets at $\delta 3.16$ and $2.90 \mathrm{ppm}$ (each one integrating for one proton) and four novel doublets appearing at $\delta 1.26$, $1.28,1.33$ and 1.35 that correspond to four methyl groups (Figure 7). The gHSQC spectrum showed the presence of two small signals appearing at $\delta 159.9 \mathrm{ppm}$ and $106.4 \mathrm{ppm}$ corresponding to quaternary carbons compatible with the double bond present in $\mathbf{2 1}$.

\section{FIGURE 7. Observed correlations from the gHMBC spectrum of 21}

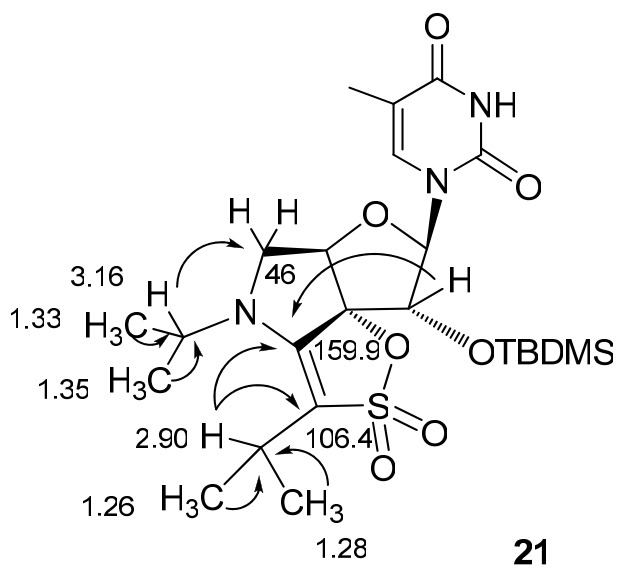

Crucial information came from the gHMBC analysis. In particular this experiment showed that the two $\mathrm{CH}_{3}$ protons at $\delta 1.26,1.28 \mathrm{ppm}$ and the $\mathrm{CH}$ proton at $\delta 2.90 \mathrm{ppm}$ belong to one isopropyl fragment. The correlations observed between the $\mathrm{CH}$ proton at $\delta 2.90 \mathrm{ppm}$ and the two vinylic carbons ( $\delta 159.9$ and $106.4 \mathrm{ppm})$ indicates unambiguously that this isopropyl fragment is attached to the southern part of the molecule. In addition, the two $\mathrm{CH}_{3}$ protons at 
$\delta 1.33$ and $1.35 \mathrm{ppm}$ and the $\mathrm{CH}$ proton at $\delta 3.16 \mathrm{ppm}$ belongs to a second isopropyl fragment that is attached to the $\mathrm{NH}$ of the pyrrolidine ring judging by the long-range correlation observed between the $\mathrm{CH}$ proton at $\delta 3.16 \mathrm{ppm}$ and the $\mathrm{C}-5^{\prime}$ carbon ( $\left.\delta 46 \mathrm{ppm}\right)$.

Finally, the scope of the reaction was briefly examined using a small set of ketones. Thus, simple aliphatic ketones (2-butanone, 3-pentanone), as well as the $\alpha, \beta$-unsaturated ketone (methyl vinyl ketone) were reacted with 3 (Schemes 7 and 8).

Reaction of $\mathbf{3}$ with 2-butanone at room temperature or in presence of acetic acid only gave complex mixtures of compounds (Scheme 7). However, addition of triethylamine gave two compounds $22(14 \%)$ and $23(16 \%)$ together with the bicyclic nucleoside 4 (16\%). Comparison of the ${ }^{1} \mathrm{H}$ NMR spectra of 22 and 23 with those of 5 and $\mathbf{6}$ revealed that their structure is similar to those of compound 5 since their spectra only differ in the signals corresponding to the ketone moiety (ethyl instead of methyl).

\section{SCHEME 7. Reaction of 3 with 2-butanone and 3-pentanone}

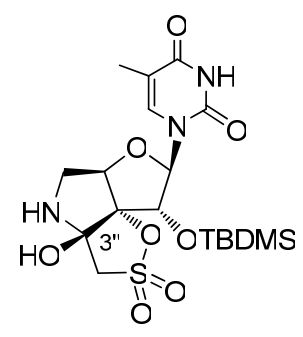

3
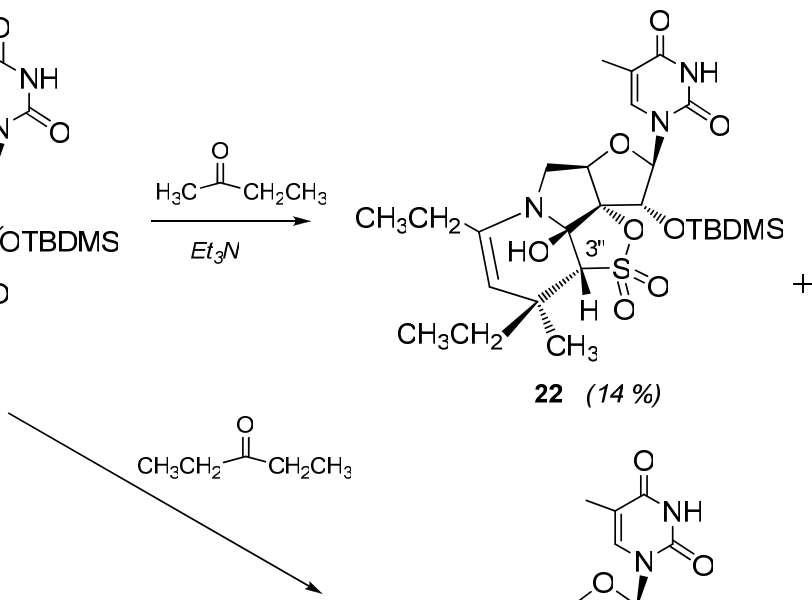

22 (14\%)

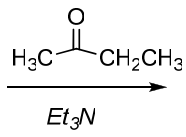

$$
22
$$

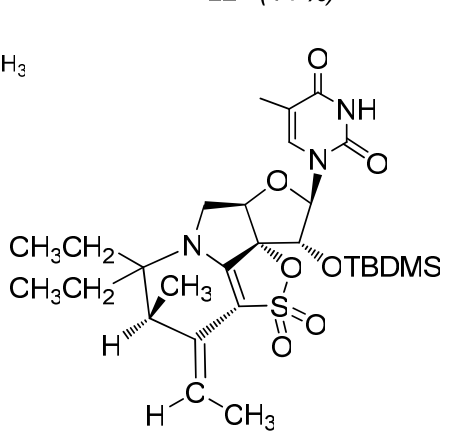

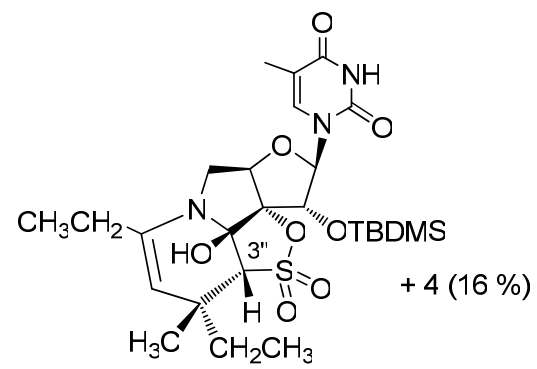

$23(16 \%)$ 
The stereochemistry of the novel stereogenic center was established as $S$ for compound 22 and $R$ for compound 23 on the basis of ROESY experiments (Figure 8). Thus, in 22 the signal at $\delta 3.54 \mathrm{ppm}$ has a correlation with the $\mathrm{H}-2^{\prime}$ of the furanose ring and the $\mathrm{CH}_{2}$ and $\mathrm{CH}_{3}$ protons of the ethyl moiety indicating that all of these protons were at the same upper side of the furanose ring. In 23 the signal at $\delta 3.52 \mathrm{ppm}$ has a correlation with the H-2' and the $\mathrm{CH}_{3}$ protons of the methyl moiety indicating that these protons were at the same upper side of the furanose ring.

a

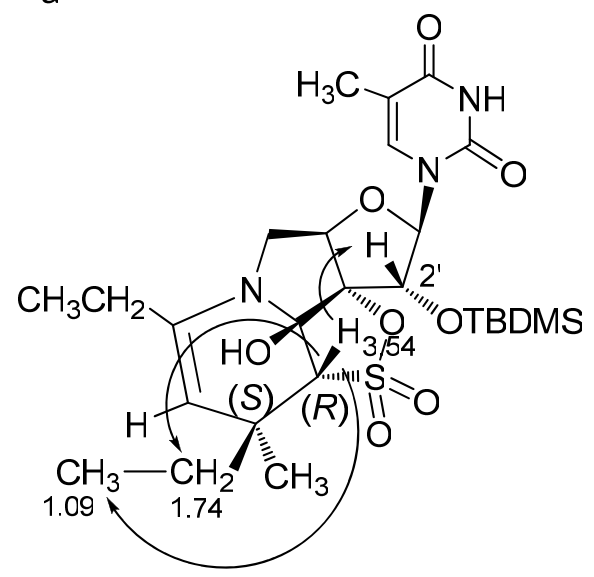

b

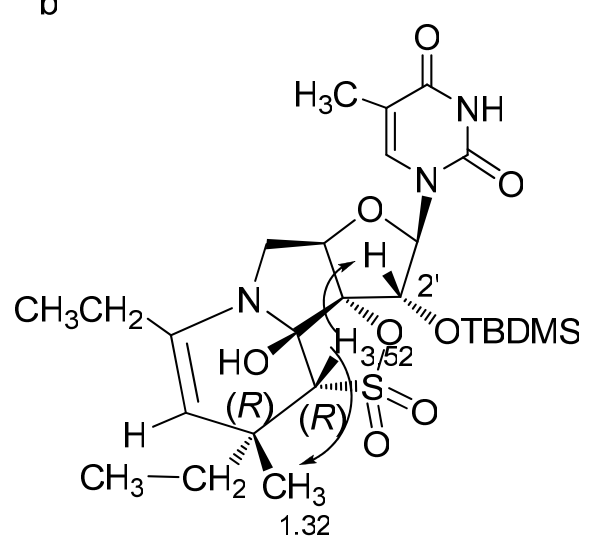

FIGURE 8. (a) Correlations observed from ROESY experiment of compound 22. (b) Correlations observed from ROESY experiment of compound 23.

On the other hand, when compound 3 was treated with 3-pentanone no transformation was observed at room temperature. Only heating at $80{ }^{\circ} \mathrm{C}$ during 3 days afforded compound 24 in $14 \%$ yield. Addition of acetic acid or triethyl amine gave complex mixtures of compounds.

In the ${ }^{1} \mathrm{H}$ NMR spectrum of 24 we observed the presence of a novel quadruplet at $\delta 5.50$ ppm integrating for a proton that in the gHSQC experiment correlates with a novel carbon at $\delta 123.9 \mathrm{ppm}$, so this signal might correspond to a vinylic proton coupled with a $\mathrm{CH}_{3}$. This vinylic proton showed in the gHMBC experiment (Figure 9a) correlations with carbons that 
belong to the novel fused ring: $\delta 15.4\left(\mathrm{CH}_{3}\right), 130.5(=\mathrm{C}), 40.2(\mathrm{CH})$ ppm and a quaternary carbon at $\delta 97.9 \mathrm{ppm}$ that belongs to the carbon adjacent to the $\mathrm{SO}_{2}$ of the nucleosidic fragment indicating that the vinylic moiety is attached at the southern part of the molecule. On the other hand, the gHMBC analysis showed the presence of two ethyl moieties with signals at $\delta 0.96,0.98,1.51$ and $1.81 \mathrm{ppm}$ that correlates with a quaternary carbon at $\delta 65.6$ ppm indicating that all of these signals belong to the same isopentyl fragment. Both, the isopentyl and vinylic fragments correlate with a $\mathrm{CH}$ carbon at $\delta 40.2 \mathrm{ppm}$ indicating that both fragments are connected through this primary carbon.

The stereochemistry of the double bond was established on the basis of a nuclear Overhauser enhancement (NOE) experiment which also confirmed the stereochemistry of the newly formed stereogenic center (Figure 9b). Thus, irradiation at $\delta 5.5 \mathrm{ppm}$ (olefinic proton) resulted in a $3.2 \%$ enhancement in the signal at $\delta 2.29 \mathrm{ppm}$ for the adjacent $\mathrm{CH}$ proton (CH-4"', ). In addition, the observed enhancement is an indication that the $\mathrm{CH}_{3}$ of the stereogenic center is above the plane of the furanose ring, whereas the H proton is below the plane. This enhancement was not possible in the opposite configuration $\left(\mathrm{CH}_{3}\right.$ below the plane). On the other hand, irradiation at $\delta 4.24 \mathrm{ppm}\left(\mathrm{H}-5^{\prime}\right.$ proton) and at $\delta 0.81 \mathrm{ppm}\left(\mathrm{CH}_{3}\right.$ of the stereogenic center) resulted in enhancements in the signal at $\delta 1.81 \mathrm{ppm}\left(\mathrm{CH}_{2}\right.$ of one of the ethyl moieties attached on the nitrogen of the pyrrolidine ring) confirming the structure proposed for 24 . 

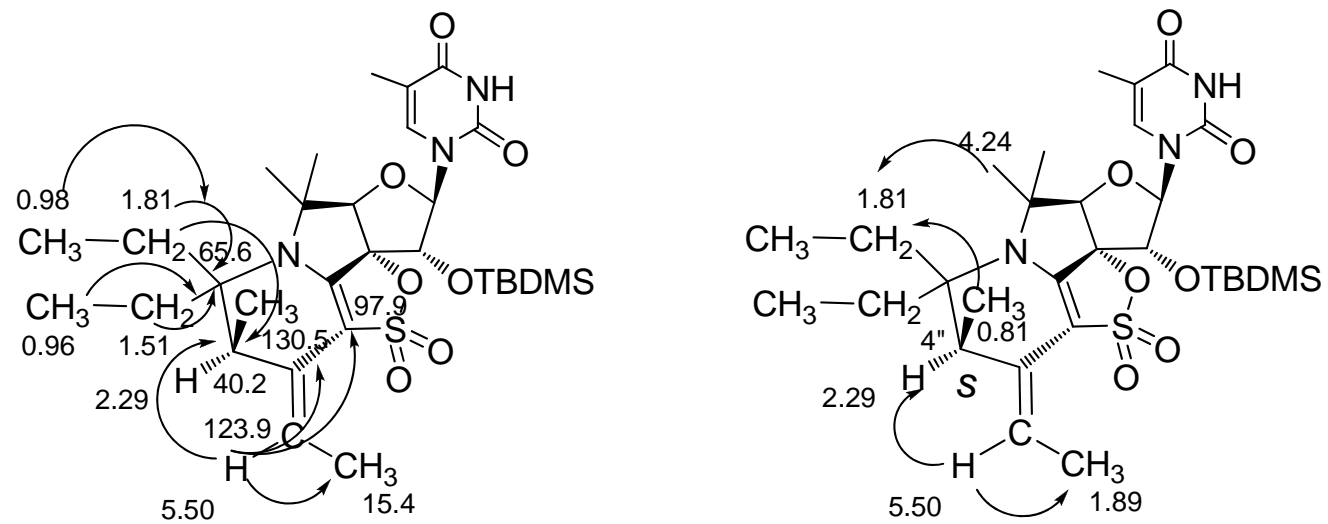

FIGURE 9. (a) Observed correlations from gHMBC of 24. Observed correlations due to signal at $\delta 5.50 \mathrm{ppm}$ (b) Correlations observed from a NOE experiment of compound 24. Assignment of stereochemistry of the new stereogenic center created at C-4"' and the double bond

Formation of $\mathbf{2 4}$ can be explained through the iminium pathway (Scheme 8). In this case the iminium intermediate 25 can be formed. The oxygen $(\mathrm{O}-)$ at the $\alpha$ position of the pyrrolidine ring may accept a proton from the neighboring ethyl group to give 26 that evolves towards 27. Finally, a concerted intramolecular cyclization, promoted by iminium catalysis might give $\mathbf{2 8}$ whose dehydratation might afford $\mathbf{2 4}$.

SCHEME 8. Proposed evolution of 3 towards 24 

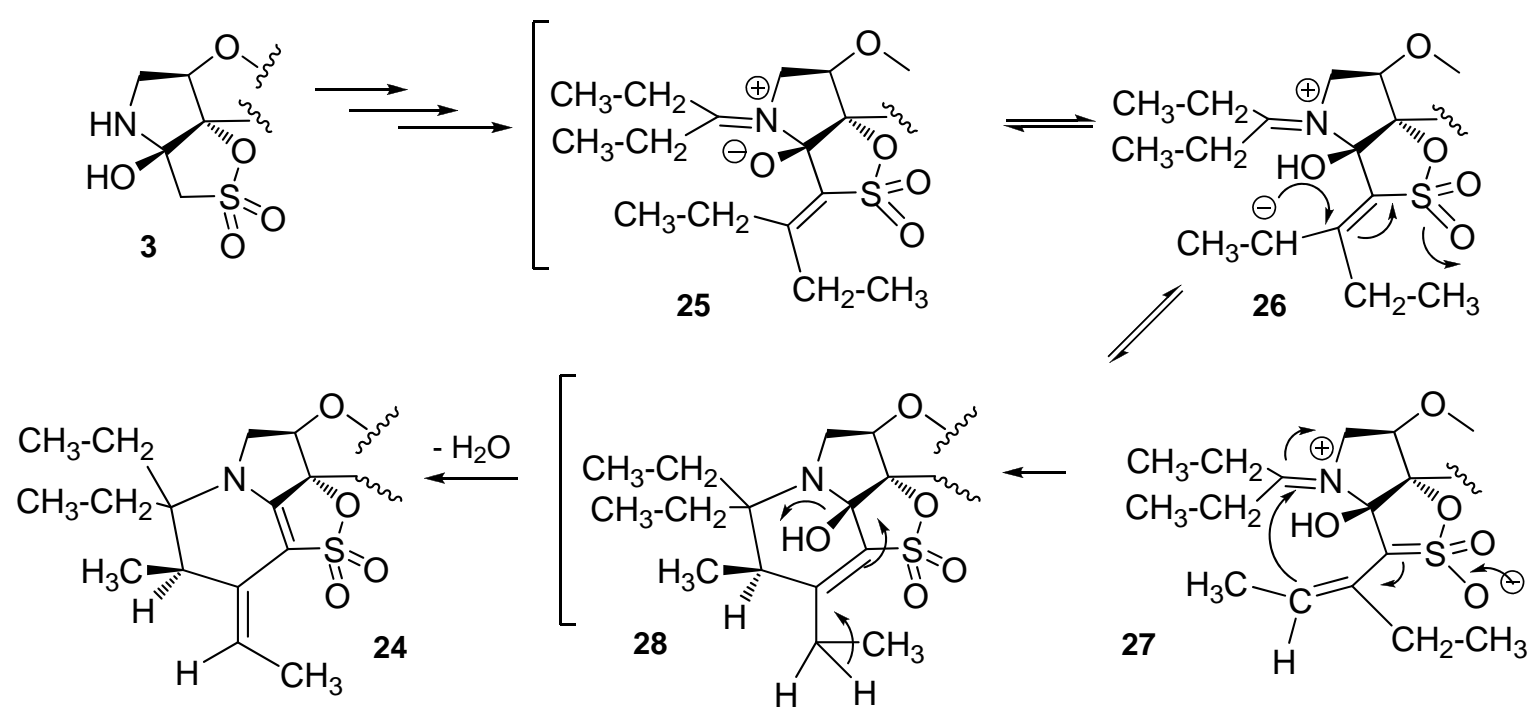

All of these experimental results can be interpreted as evidence that the reaction between 3 and a small ketone such as acetone takes place much easier than the same reaction with larger ketones. In some cases, as for example with 2-butanone, the addition of a base as triethylamine might facilitate the abstraction of one of the acidic protons adjacent to the $\mathrm{SO}_{2}$, as it was previously observed in our group. ${ }^{15}$ In other cases, as with 3-pentanone the reaction needs to be heated.

In addition, our results clearly indicate that the added triethylamine should facilitate the enamine pathway and therefore the formation of compounds with structure similar to 5 (Scheme 4). To check that hypothesis the reaction between 3 and acetone was repeated in presence of triethylamine. In this reaction only compound 5 was obtained in excellent $(80 \%)$ yield after 4 hours of reaction. Thus, the enamine pathway is favoured in the presence of an acid (acetic acid) or a base (triethylamine).

Finally, reaction of 3 with 3-buten-2-one (methyl vinyl ketone) afforded the hydroxy tricyclic nucleoside $29(59 \%)$. The ${ }^{1}$ H NMR spectrum of 29 in benzene- $d_{6}$ is consistent with the structure proposed for this compound, however in more polar solvents such as: acetone$d_{6}$, methanol- $d_{4}$ and acetonitrile- $d_{3}$, we observed that $\mathbf{2 9}$ was transformed in the substituted $\gamma$-lactam 31 evidencing that a spontaneous opening of the spiro sultone ring has been 
achieved in these solvents. As it will be shown in the experimental part, this opening depends on the polarity of the solvent. Thus, in a polar solvent as methanol- $d_{4}$ the opening of the spiro sultone ring proceeds rapidly, in a few minutes, however in less polar solvents such as acetonitrile- $d_{3}$ and DMSO- $d_{6}$ the opening requires hours.

\section{SCHEME 9. Reaction of 3 with methyl vinyl ketone}

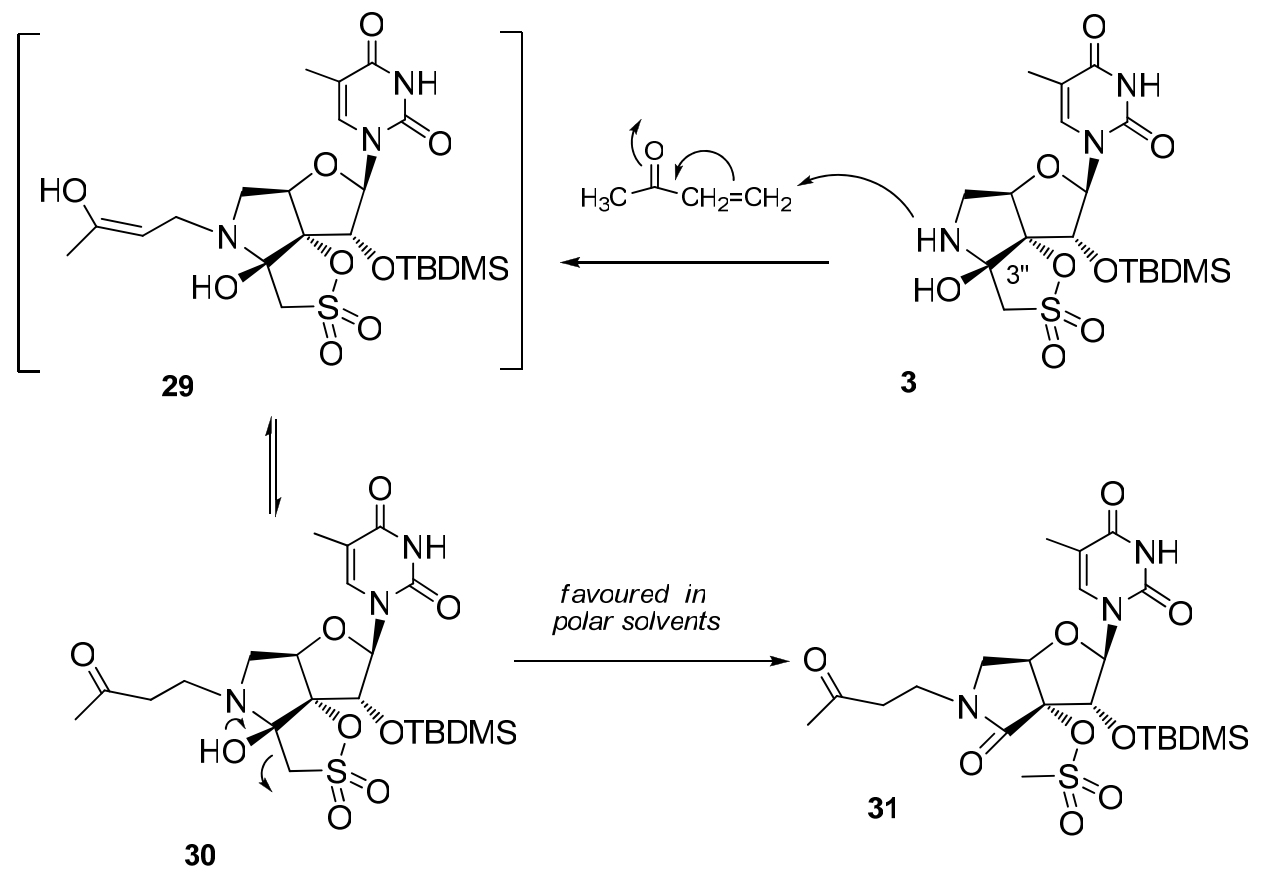

The experimental result obtained with the $\alpha, \beta$-unsaturated ketone (methyl vinyl ketone) can be also explained in the context of the proposed mechanism. In this case, the 1,4 attack is favoured over the 1,2 addition to give the enol $\mathbf{2 9}$ that tautomerizes to the keto derivative 30, consequently no iminium ion will be formed and the subsequent attack of a second molecule of ketone at the southern hemisphere of the molecule was not observed. The opening of the sultone ring present in $\mathbf{3 0}$ was observed, particularly in polar solvents to afford the substituted $\gamma$-lactam 31.

Our experimental results indicate that the nature of the ketone $\left(\mathrm{R}^{1} \mathrm{COR}^{2}\right)$ is critical for the attack of the $\mathrm{NH}$ of the pyrrolidine ring present in $\mathbf{3}$ and the subsequent cyclization. 
Different types of ketones can be attacked by the $\mathrm{NH}$ of the pyrrolidine ring present in $\mathbf{3}$, however only with acetone this attack and the subsequent cyclization proceed spontaneously. When the reaction with ketones is disfavoured other compounds were isolated. Thus, if the opening of the spiro moiety is faster than the attack of the NH to the ketone the bicyclic derivative 4 was also formed.

\section{Conclusions}

In summary, the carefully controlled hydrolysis of enamine sultone $\mathbf{1}$ afforded the hemiaminal 3. The unexpected reaction of 3 with acetone allowed its efficient transformation into novel fused tetracyclic nucleosides 5 and $\mathbf{6}$ with rather unusual molecular skeletons in a completely regio- and stereoselective manner. In this process, two novel carbon-carbon bonds were formed spontaneously in a one-pot fashion. For the formation of $\mathbf{5}$ and $\mathbf{6}$ we propose an enamine-iminium mechanism involving carbinolamine, iminium ion and enamine intermediates in which the protons transfers that take place are mediated by the hydroxyl functionality at the $\alpha$ position of the pyrrolidine ring, suggesting that this $\mathrm{OH}$ is crucial for the progress of the reaction. Acetic acid and triethylamine promote the enamine pathway (formation of 5) and accelerates the reaction rate. The combination of NMR and HPLC-ESI-MS techniques revealed that the reaction proceed through an enamine-iminium mechanism which was unequivocally confirmed by the presence of the iminium carbon signal at $\delta 191.2 \mathrm{ppm}$ in the ${ }^{13} \mathrm{C}$ NMR spectrum. In addition, some of the proposed intermediates were trapped using hydrogenation experiments.

The scope of the reaction was also examined concluding that the nature of the ketone $\left(\mathrm{R}^{1} \mathrm{COR}^{2}\right)$ is critical for the attack of the $\mathrm{NH}$ of the pyrrolidine ring present in $\mathbf{3}$ and the subsequent cyclization. Different types of ketones can be attacked by the $\mathrm{NH}$ of the pyrrolidine ring present in $\mathbf{3}$, however only with acetone this attack and the subsequent cyclization proceeds spontaneously. 
Based on the results we have obtained in this paper we propose that the $\alpha$-hydroxy pyrrolidine tricyclic nucleoside $\mathbf{3}$ can be a particularly attractive synthetic intermediate for the efficient creation of molecular complexity.

\section{Experimental section}

The names of polycyclic furanoses in this section are given according to the IUPAC recommendations for polycyclic compounds (extension of the Von Baeyer system). ${ }^{16}$ However, for easy comparison, the assignments of the signals of the NMR spectra follow standard nucleoside numbering (i.e., the furanose skeleton numbered 1'-5' and the thymine nucleobase numbered 1-6). The spirosultone skeleton was numbered 1"-4" starting from the oxygen. The novel fused ring was numbered 1",'-7', taking into consideration the length and the presence of a double bond. 


\section{$5^{\prime}, N^{4 \prime}$-Cyclo-[1-[2'-O-(tert-butyldimethylsilyl)-5'-deoxy- $\beta$-D-ribofuranosyl]thymine]-3'-spiro-5'”-}

(4'’-amino-4"'-S-hydroxy-1",2"'-oxathiolane-2",2"'-dioxide) (3). A solution of enamino sultone $\mathbf{1}^{4}$ (100 mg, $0.22 \mathrm{mmol})$ in a mixture water/ acetonitrile $(1: 1)(4 \mathrm{~mL})$ was acidified by addition of acetic acid until $\mathrm{pH} \sim 5$. The reaction mixture was then heated at $80{ }^{\circ} \mathrm{C}$ for $8 \mathrm{~h}$. Volatiles were removed at reduced pressure and the crude was purified by CCTLC (polar gradient on elution, from hexane/EtOAc, 1:1 up to hexane/ EtOAc, 1:10 as eluent) to afford $3(100 \mathrm{mg}, 93 \%)$ as a white amorphous foam. ${ }^{1} \mathrm{H}$ NMR [300 MHz, acetone- $d_{6}$, sample freshly prepared prior to analysis] $\delta: 0.01$ and $0.14(2 \mathrm{~s}, 6 \mathrm{H}$, $2 \mathrm{CH}_{3}$ ), 0.87 (s, 9H, t-But), $1.86\left(\mathrm{~s}, 3 \mathrm{H}, \mathrm{CH}_{3}-5\right), 3.21$ (dd, $1 \mathrm{H}, \mathrm{H}-5^{\prime} \mathrm{a}, J_{4^{\prime}, 5^{\prime} \mathrm{a}}=2.2 \mathrm{~Hz} ; J_{5^{\prime}, 5^{\prime} b}=11.9 \mathrm{~Hz}$ ), $3.42\left(\mathrm{dd}, 1 \mathrm{H}, \mathrm{H}-5^{\prime} \mathrm{b}, J_{4^{\prime}, 5^{\prime} b}=5.1 \mathrm{~Hz} ; J_{5^{\prime}, 5^{\prime} b}=11.9 \mathrm{~Hz}\right), 3.61\left(\mathrm{~d}, 1 \mathrm{H}, \mathrm{H}-3^{\prime}{ }^{\prime} \mathrm{a}, J_{3^{\prime \prime}, 3^{\prime \prime} b}=13.9 \mathrm{~Hz}\right), 3.85(\mathrm{~d}$, 1H, H-3”b, $\left.J_{3}{ }^{\prime \prime}, 3^{\prime \prime b}=13.9 \mathrm{~Hz}\right), 4.56$ (m, 1H, H-4'), 4.88 (d, 1H, H-2', $J_{1^{\prime}, 2}$ = $\left.6.9 \mathrm{~Hz}\right), 5.98$ (d, 1H, H-1', $\left.J_{1,2},=6.9 \mathrm{~Hz}\right), 6.13$ (br s, 1H, OH-4"), $7.58(\mathrm{~s}, 1 \mathrm{H}, \mathrm{H}-6), 10.24$ (br s, 1H, NH).

${ }^{1} \mathrm{H}-\mathrm{NMR}\left(300 \mathrm{MHz}, \mathrm{CDCl}_{3}\right) \delta: 0.02$ and $0.08\left(2 \mathrm{~s}, 6 \mathrm{H}, 2 \mathrm{CH}_{3}\right), 0.88$ (s, $\left.9 \mathrm{H}, t-\mathrm{But}\right), 1.95$ (s, 3H, $\mathrm{CH}_{3}-$ 5), $3.27\left(\mathrm{dd}, 1 \mathrm{H}, \mathrm{H}-5^{\prime} \mathrm{a}, J_{4^{\prime}, 5^{\prime} a}=1.1 \mathrm{~Hz} ; J_{5^{\prime} a, 5^{\prime} b}=9.6 \mathrm{~Hz}\right), 3.39$ (dd, $1 \mathrm{H}, \mathrm{H}-5^{\prime} b, J_{4^{\prime}, 5^{\prime} b}=3.3 \mathrm{~Hz} ; J_{5^{\prime} a, 5^{\prime} b}=$ $9.6 \mathrm{~Hz}), 3.53$ (d, 1H, H-3"a, $\left.J_{3 " a, 3 " b}=10.2 \mathrm{~Hz}\right), 3.62$ (d, 1H, H-3"b, $\left.J_{3 " a, 3 " b}=10.2 \mathrm{~Hz}\right), 4.56$ (dd, 1H, H$\left.4^{\prime}, J_{4^{\prime}, 5^{\prime} a}=1.1 \mathrm{~Hz} ; J_{4^{\prime}, 5^{\prime} b}=3.3 \mathrm{~Hz}\right), 5.12\left(\mathrm{~d}, 1 \mathrm{H}, \mathrm{H}-2^{\prime}, J_{1^{\prime}, 2^{\prime}}=3.9 \mathrm{~Hz}\right), 5.32\left(\mathrm{~d}, 1 \mathrm{H}, \mathrm{H}-1^{\prime}, J_{1^{\prime}, 2^{\prime}}=3.9 \mathrm{~Hz}\right)$, 7.08 (s, 1H, H-6), 8.78 (br s, 1H, NH). ${ }^{13} \mathrm{C}-\mathrm{NMR}\left(75 \mathrm{MHz}, \mathrm{CDCl}_{3}\right) \delta: 47.5\left(\mathrm{CH}_{2}\right), 56.7\left(\mathrm{CH}_{2}\right), 71.2$ (CH), $83.9(\mathrm{CH}), 95.8(\mathrm{C}), 97.3(\mathrm{C}), 98.8(\mathrm{CH}), 112.2(\mathrm{C}-5), 139.1(\mathrm{C}-6), 150.3(\mathrm{CO}), 163.7(\mathrm{CO}) . \mathrm{MS}$ $\left(\mathrm{ESI}^{+}\right) \mathrm{m} / \mathrm{z}: 476.1[\mathrm{M}+\mathrm{H}]^{+}(100 \%)$. Anal. Calcd for $\mathrm{C}_{18} \mathrm{H}_{29} \mathrm{~N}_{3} \mathrm{O}_{8} \mathrm{SSi}$ : C, 45.46; H, 6.15; N, 8.84. Found: C, 45.54; H, 6.32; N, 8.68. HPLC: $t_{R}=8.3$ min. TLC (EtOAc / MeOH, 9:1) Rf: 0.33 (heating, vanillin). Falta señal del OH-ERNESTO 
(1R,3R,4R,5R)-4-(tert-butyldimethylsilyloxy)-5-mesyloxy-6-oxo-3-(thymin-1'-yl)-7-aza-2-

oxabicyclo[3.3.0] octane (4). ${ }^{4}$ To a solution of $3(100 \mathrm{mg}, 0.21 \mathrm{mmol})$ in acetonitrile $(4 \mathrm{~mL})$ was added potassium carbonate $(3 \mathrm{mg}, 0.021 \mathrm{mmol})$. The reaction was refluxed for $10 \mathrm{~h}$ and evaporated to dryness. The residue was dissolved in ethyl acetate $(20 \mathrm{~mL})$ and washed with water $(2 \times 20 \mathrm{~mL})$. The organic layer was dried $\left(\mathrm{Na}_{2} \mathrm{SO}_{4}\right.$, filtered and evaporated to dryness to give, after purification by CCTLC on the chromatotron (hexane/ethyl acetate, $1: 1), 80 \mathrm{mg}(80 \%)$ of $4^{4}$

5', $N^{4 "}$-Cyclo-[1-[2'-O-(tert-butyldimethylsilyl)-5'-deoxy- $\beta$-D-ribofuranosyl]thymine]-3'-spiro-5'”-

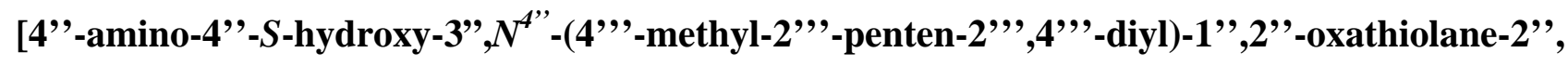
2'’-dioxide] (5) and 5', $N^{4}$ ' -cyclo-[1-[2'-O-(tert-butyldimethylsilyl)-5'-deoxy- $\beta$-D-

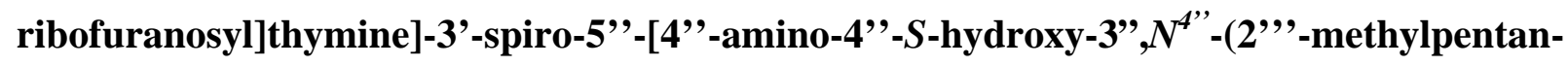
2"',4",,4"'-triyl)-1",2"'-oxathiolane-2",2"'-dioxide] (6). A solution of nucleoside 3 (100 mg, 0.21 $\mathrm{mmol})$ in acetone $(2 \mathrm{~mL})$ was stirred at room temperature for $24 \mathrm{~h}$. Then, the solvent was evaporated under reduced pressure and the residue was purified by CCTLC using (hexane/EtOAc, 1:1) as eluent. From the fastest moving band, $40 \mathrm{mg}$ of 5 (35\%) was isolated as a white solid. M.p. $132-134{ }^{\circ} \mathrm{C} .{ }^{1} \mathrm{H}-$ NMR (300 MHz, acetone- $\left.d_{6}\right) \delta: 0.07$ and $0.15\left(2 \mathrm{~s}, 6 \mathrm{H}, 2 \mathrm{CH}_{3}\right), 0.88(\mathrm{~s}, 9 \mathrm{H}, t-\mathrm{But}), 1.35\left(\mathrm{~s}, 3 \mathrm{H}, \mathrm{CH}_{3}\right)$, 1.36 (s, 3H, $\left.\mathrm{CH}_{3}\right), 1.78$ (s, 3H, $\left.\mathrm{CH}_{3}\right), 1.80$ (s, 3H, $\left.\mathrm{CH}_{3}-5\right), 3.45$ (s, 1H, H-3’’), 3.62 (dd, 1H, H-5'a, J4',5'a $\left.=5.7 \mathrm{~Hz} ; J_{5}{ }^{\prime} a, 5^{\prime} b=11.4 \mathrm{~Hz}\right), 3.82\left(\mathrm{~d}, 1 \mathrm{H}, \mathrm{H}-5^{\prime} \mathrm{b}, J_{5}{ }^{\prime} a, 5^{\prime} b=11.4 \mathrm{~Hz}\right), 4.41(\mathrm{~s}, 1 \mathrm{H}), 4.65\left(\mathrm{~d}, 1 \mathrm{H}, \mathrm{H}-4^{\prime}, J_{4^{\prime}, 5^{\prime} a}\right.$ $=5.7 \mathrm{~Hz}), 5.01\left(\mathrm{~d}, 1 \mathrm{H}, \mathrm{H}-2^{\prime}, J_{1^{\prime}, 2},=5.6 \mathrm{~Hz}\right), 5.91(\mathrm{~s}, 1 \mathrm{H}, \mathrm{OH}), 5.97\left(\mathrm{~d}, 1 \mathrm{H}, \mathrm{H}-1^{\prime}, J_{1^{\prime}, 2},=5.6 \mathrm{~Hz}\right), 7.66$ (s, 1H, H-6), 10.11 (br s, 1H, NH). ${ }^{13} \mathrm{C}-\mathrm{NMR}(75 \mathrm{MHz} \text {, acetone-d })_{6} \delta:-5.1\left(\mathrm{CH}_{3}\right),-4.6\left(\mathrm{CH}_{3}\right), 12.3$ $\left(\mathrm{CH}_{3}\right), 19.3\left(\mathrm{CH}_{3}\right), 18.6(\mathrm{C}), 25.8\left(\mathrm{CH}_{3}\right), 26.1\left(\mathrm{CH}_{3}\right), 30.9\left(\mathrm{CH}_{3}\right), 32.3(\mathrm{C}), 53.0\left(\mathrm{CH}_{2}\right), 66.4(\mathrm{CH}), 72.9$ $(\mathrm{CH}), 81.7(\mathrm{CH}), 91.7(\mathrm{CH}), 93.0(\mathrm{C}), 94.4(\mathrm{C}), 107.4(\mathrm{C}=), 112.1(\mathrm{C}-5), 134.7(\mathrm{C}=), 136.8(\mathrm{C}-6), 151.3$ (CO), $163.7(\mathrm{CO}) . \mathrm{MS}\left(\mathrm{ESI}^{+}\right) \mathrm{m} / \mathrm{z}: 574\left[\mathrm{M}+\mathrm{NH}_{4}\right]^{+}(100 \%), 556.1[\mathrm{M}+\mathrm{H}]^{+}(85 \%)$. Anal. Calcd for $\mathrm{C}_{24} \mathrm{H}_{37} \mathrm{~N}_{3} \mathrm{O}_{8} \mathrm{SSi}: \mathrm{C}, 51.87 ; \mathrm{H}, 6.71 ; \mathrm{N}, 7.56$. Found: C, 51.69; H, 6.86; N, 7.81. HPLC: $t_{R}=13.70$ min.TLC (hexane / EtOAc, 1:2) Rf: 0.54 (heating). 
From the slowest moving band, $30 \mathrm{mg}$ of $6(30 \%)$ was isolated as a foam. ${ }^{1} \mathrm{H}-\mathrm{NMR}(300 \mathrm{MHz}$, acetone- $\left.d_{6}\right) \delta: 0.07$ and $0.15\left(2 \mathrm{~s}, 6 \mathrm{H}, 2 \mathrm{CH}_{3}\right), 0.89(\mathrm{~s}, 9 \mathrm{H}, t-\mathrm{But}), 1.26\left(\mathrm{~s}, 3 \mathrm{H}, \mathrm{CH}_{3}\right), 1.44\left(\mathrm{~s}, 3 \mathrm{H}, \mathrm{CH}_{3}\right)$, $1.86\left(\mathrm{~s}, 3 \mathrm{H}, \mathrm{CH}_{3}-5\right), 2.14$ (s, 3H, $\left.\mathrm{CH}_{3}\right), 2.34$ (d, $\left.1 \mathrm{H}, \mathrm{CH}_{2}, J=19.1 \mathrm{~Hz}\right), 2.48\left(\mathrm{~d}, 1 \mathrm{H}, \mathrm{CH}_{2}, J=19.1 \mathrm{~Hz}\right)$ $2.67\left(\mathrm{dd}, 1 \mathrm{H}, \mathrm{H}-5^{\prime} \mathrm{a}, J_{4^{\prime}, 5^{\prime} a}=4.5 \mathrm{~Hz}, J_{5^{\prime}, 5^{\prime} b}=11.7 \mathrm{~Hz}\right), 3.29$ (d, 1H, H-5'b, $\left.J_{5^{\prime}, 5^{\prime} b}=11.7 \mathrm{~Hz}\right), 4.36$ (d, $\left.1 \mathrm{H}, \mathrm{H}-4^{\prime}, J_{4^{\prime}, 5^{\prime} a}=4.5 \mathrm{~Hz}\right), 4.92\left(\mathrm{~d}, 1 \mathrm{H}, \mathrm{H}-2^{\prime}, J_{1^{\prime}, 2^{\prime}}=4.8 \mathrm{~Hz}\right), 5.39$ (s, 1H, OH), 5.85 (d, 1H, H-1', $J_{1^{\prime}, 2^{\prime}}=$ $4.8 \mathrm{~Hz}), 7.66(\mathrm{~s}, 1 \mathrm{H}, \mathrm{H}-6), 10.07(\mathrm{br} \mathrm{s}, 1 \mathrm{H}, \mathrm{NH}) .{ }^{13} \mathrm{C}-\mathrm{NMR}\left(75 \mathrm{MHz}\right.$, acetone- $\left.d_{6}\right) \delta:-4.7\left(\mathrm{CH}_{3}\right),-4.6$ $\left(\mathrm{CH}_{3}\right), 12.7\left(\mathrm{CH}_{3}\right), 18.6(\mathrm{C}), 19.3\left(\mathrm{CH}_{3}\right), 26.1\left(\mathrm{CH}_{3}\right), 29.0\left(\mathrm{CH}_{3}\right), 31.4\left(\mathrm{CH}_{3}\right), 40.0\left(\mathrm{CH}_{2}\right), 50.4\left(\mathrm{CH}_{2}\right)$, $53.3(\mathrm{C}), 75.1(\mathrm{CH}), 82.1(\mathrm{CH}), 91.5(\mathrm{CH}), 92.1(\mathrm{C}), 96.1(\mathrm{C}), 110.7(\mathrm{C}-5), 126.7(\mathrm{C}=), 136.9(\mathrm{C}-6)$, $147.8(\mathrm{C}=), 151.5(\mathrm{CO}), 164.1(\mathrm{CO}) . \mathrm{MS}\left(\mathrm{ESI}^{+}\right) \mathrm{m} / \mathrm{z} 556.1[\mathrm{M}+\mathrm{H}]^{+}$. Anal. Calcd for $\mathrm{C}_{24} \mathrm{H}_{37} \mathrm{~N}_{3} \mathrm{O}_{8} \mathrm{SSi}: \mathrm{C}$, 51.87; H, 6.71; N, 7.56; Found: C, 51.73; H, 6.88; N, 7.74 . HPLC: $t_{R}=13.21 \mathrm{~min}$. TLC (hexane / EtOAc, 1:2 ) Rf: 0.33 (heating).

Selective method for the synthesis of 5 . A) In the presence of acetic acid. Acetic acid was added over acetone $(2 \mathrm{~mL})$ until $\mathrm{pH} \sim 5$. Hydroxynucleoside $3(100 \mathrm{mg}, 0.21 \mathrm{mmol})$ was allowed to dissolve in this acidified solution and the mixture was efficiently stirred at room temperature for $24 \mathrm{~h}$. After that, volatiles were eliminated at reduced pressure and the crude was purified by CCTLC using hexane/EtOAc, 1:1 as eluent to afford $99 \mathrm{mg}$ of $\mathbf{5}(85 \%)$. B) In the presence of triethylamine. A solution of the hydroxynucleoside $3(50 \mathrm{mg}, 0.1 \mathrm{mmol})$ in acetone $(2.5 \mathrm{~mL})$ and triethylamine $(0.05 \mathrm{~mL})$ was stirred at room temperature for $4 \mathrm{~h}$. Then, the solvent was evaporated under reduced pressure and the residue was purified by CCTLC using (hexane/EtOAc, 1:1) as eluent to afford $46 \mathrm{mg}$ of 5 (80\%).

\section{5', $N^{4 \prime}$-Cyclo-[1-[2'-O-(tert-butyldimethylsilyl)-5'-deoxy- $\beta$-D-ribofuranosyl]-thymine]-3'-} spiro-5"'-(4"'-amino-4"'S-methoxy-1",2''-oxathiolane-2"', 2"'-dioxide) (7). A solution of $\mathbf{1}^{4}$ (0.1 g, $0.23 \mathrm{mmol})$ in methanol $(3 \mathrm{~mL})$ was heated in a sealed tube at $80^{\circ} \mathrm{C}$ for $16 \mathrm{~h}$. After evaporation of the solvent, the residue was purified by CCTLC on the chromatotron (hexane:ethyl acetate, 1:2) to give 0.06 
$\mathrm{g}(58 \%)$ of 7 as a white foam. ${ }^{1} \mathrm{H}$ NMR $\left[300 \mathrm{MHz},\left(\mathrm{CD}_{3}\right)_{2} \mathrm{CO}\right] \delta: 1.85$ (s, 3H), 3.20 (m, $1 \mathrm{H}, \mathrm{H}-5$ ' a), 3.43 (s, 3H, $\left.\mathrm{OCH}_{3}\right), 3.45$ (m, 1H, H-5'b), 3.62 (d, 1H, H-3”a, $\left.J_{3 " a, 3 " b}=13.6 \mathrm{~Hz}\right), 3.77$ (t, NH), 3.97 (d, 1H, H-3”b), $4.64\left(\mathrm{dd}, 1 \mathrm{H}, \mathrm{H}-4^{\prime}, J_{4^{\prime}, 5^{\prime} a}=4.6 \mathrm{~Hz}, J_{4^{\prime}, 5^{\prime} \mathrm{a}}=6.1 \mathrm{~Hz}\right), 4.88\left(\mathrm{~d}, 1 \mathrm{H}, \mathrm{H}-2^{\prime}\right), 6.03$ (d, 1H, $J_{1^{\prime}, 2}{ }^{\prime}=6.7$ $\mathrm{Hz}), 7.54(\mathrm{~s}, 1 \mathrm{H}) .{ }^{13} \mathrm{C} \mathrm{NMR}\left[75 \mathrm{MHz},\left(\mathrm{CD}_{3}\right)_{2} \mathrm{CO}\right] \delta: 12.5\left(\mathrm{CH}_{3}\right), 49.5\left(\mathrm{CH}_{2}\right), 51.8\left(\mathrm{CH}_{2}\right), 54.5\left(\mathrm{OCH}_{3}\right)$, $72.9(\mathrm{CH}), 85.5(\mathrm{CH}), 92.1(\mathrm{CH}), 99.9(\mathrm{C}), 99.4(\mathrm{C}), 111.9$ (C-5), 137.6 (C-6), $152.4(\mathrm{CO}), 166.1(\mathrm{CO})$. MS (ES+) m/z $502.6(\mathrm{M}+\mathrm{Na})^{+}$. Anal. Calcd for $\mathrm{C}_{19} \mathrm{H}_{31} \mathrm{~N}_{3} \mathrm{O}_{8} \mathrm{SSi}$ : C, 46.61; H, 6.38; N, 8.58. Found: $\mathrm{C}$, 46.76; $\mathrm{H}, 6.75 ; \mathrm{N}, 8.05$. Meter $\mathrm{C} 13$ si tenemos en material suplementario

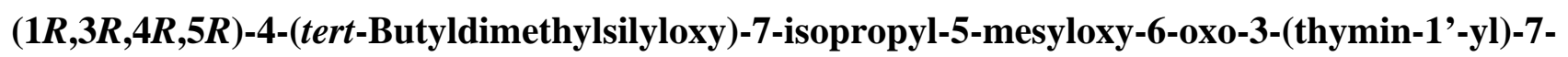

aza-2-oxabicyclo[3.3.0]octane (19). A solution of the hydroxynucleoside 3 (104 $\mathrm{mg}, 0.2 \mathrm{mmol})$ in acetone $(25 \mathrm{~mL})$ containing $\mathrm{Pd} / \mathrm{C}(10 \%)(50 \mathrm{mg})$ was hydrogenated under atmospheric hydrogen pressure for $6 \mathrm{~h}$. The reaction mixture was filtered, and the filtrate was evaporated to dryness under reduced pressure. The crude material is purified by CCTLC (polar gradient on elution, from dichloromethane $100 \%$ up to dichloromethane $/ \mathrm{MeOH}, 9: 1)$, isolating $91 \mathrm{mg}(80 \%)$ of $\mathbf{1 9}$ as a white waxy-solid. ${ }^{1} \mathrm{H}-\mathrm{NMR}\left(500 \mathrm{MHz}\right.$, acetone- $\left.d_{6}\right) \delta: 0.01$ and $0.20\left(2 \mathrm{~s}, 6 \mathrm{H}, 2 \mathrm{CH}_{3}\right), 0.87(\mathrm{~s}, 9 \mathrm{H}, t-\mathrm{Bu}), 1.17$ (d, $3 \mathrm{H}, \mathrm{CH}_{3}$ isopropyl, $\left.J=6.8 \mathrm{~Hz}\right), 1.21\left(\mathrm{~d}, 3 \mathrm{H}, \mathrm{CH}_{3}\right.$ isopropyl, $\left.J=6.8 \mathrm{~Hz}\right), 1.83\left(\mathrm{~s}, 3 \mathrm{H}, \mathrm{CH}_{3}-5\right), 3.33$ (s, $3 \mathrm{H}, \mathrm{CH}_{3} \mathrm{SO}_{2}$ ), 3.45 (dd, $1 \mathrm{H}, \mathrm{H}-5^{\prime}$ a $, J_{4^{\prime}, 5^{\prime} a}=6.6 \mathrm{~Hz}, J_{5^{\prime} a, 5^{\prime} b}=11.2 \mathrm{~Hz}$ ), 3.80 (dd, 1H, H-5'b, $J_{4^{\prime}, 5^{\prime} b}=$ $1.6 \mathrm{~Hz}, J_{5^{\prime} a 5^{\prime} b}=11.2 \mathrm{~Hz}$ ), 4.27 (sextuplet, $1 \mathrm{H}, \mathrm{CH}$ isopropyl, $J=6.8 \mathrm{~Hz}$ ), 4.60 (d, 1H, H-2', $J_{1^{\prime}, 2^{\prime}}=7.6$ Hz), 4.94 (dd, 1H, H-4', $\left.J_{4^{\prime}, 5^{\prime} a}=6.6 \mathrm{~Hz}, J_{4^{\prime}, 5^{\prime} b}=1.6 \mathrm{~Hz}\right), 5.93$ (d, $1 \mathrm{H}, \mathrm{H}-1^{\prime}, J_{1^{\prime}, 2}{ }^{\prime}=7.6 \mathrm{~Hz}$,), $7.49(\mathrm{~s}, 1 \mathrm{H}$ , H-6), 10.21 (br s, 1H, NH). ${ }^{13} \mathrm{C}-\mathrm{NMR}\left(75 \mathrm{MHz}\right.$, acetone- $\left.d_{6}\right) \delta:-3.3\left(\mathrm{CH}_{3}\right),-4.3\left(\mathrm{CH}_{3}\right), 13.3\left(\mathrm{CH}_{3}\right)$, $19.5(\mathrm{C}), 19.7\left(\mathrm{CH}_{3}\right), 20.6\left(\mathrm{CH}_{3}\right), 26.8\left(3 \mathrm{CH}_{3}\right), 42.4\left(\mathrm{CH}_{3}\right), 45.5(\mathrm{CH}), 47.3\left(\mathrm{CH}_{2}\right), 77.5(\mathrm{CH}), 80.2$ (CH), $90.1(\mathrm{C}), 90.6(\mathrm{CH}), 113.0(\mathrm{C}-5), 137.6(\mathrm{C}-6), 152.4(\mathrm{CO}), 164.8(\mathrm{CO}), 168.5(\mathrm{CO}) . \mathrm{MS}\left(\mathrm{ESI}^{+}\right)$ $m / z 518.2[\mathrm{M}+\mathrm{H}]^{+}(100 \%), 540.2[\mathrm{M}+\mathrm{Na}]^{+}(18 \%)$. HPLC: $t_{R}=10 \mathrm{~min}$. TLC $\left(\mathrm{CH}_{2} \mathrm{Cl}_{2} / \mathrm{MeOH}, 9: 1\right) \mathrm{Rf}:$ 0.58 (heating). Anal. Calcd for $\mathrm{C}_{21} \mathrm{H}_{35} \mathrm{~N}_{3} \mathrm{O}_{8} \mathrm{SSi}$ : C, 48.72; H, 6.81; N, 8.12. Found: C, 48.76; H, 6.84; N, 8.16. 
5', $N^{4 " '-C y c l o-[1-[2 '-O-(t e r t-b u t y l d i m e t h y l s i l y l)-5 '-d e o x y-~} \beta$-D-ribofuranosyl]thymine]-3'-spiro-5'”[3"'-isopropyl-4"'-isopropylamino-1",2"'-oxathiole-2"', 2"'-dioxide] (21). A solution of the hydroxynucleoside $3(50 \mathrm{mg}, 0.1 \mathrm{mmol})$ in acetone $(20 \mathrm{~mL})$ was stirred at room temperature for $7 \mathrm{~h}$. Then, $\mathrm{Pd} / \mathrm{C}(10 \% \mathrm{Pd})(25 \mathrm{mg})$ was added and the reaction mixture was hydrogenated under atmospheric hydrogen pressure overnight. The reaction mixture was filtered, and the filtrate was evaporated to dryness under reduced pressure. The crude material is purified by CCTLC (polar gradient on elution, from dichloromethane $100 \%$ up to dichloromethane $/ \mathrm{MeOH}, 10: 1)$, isolating $24 \mathrm{mg}$ (30\%) of 21 as a white waxy-solid. ${ }^{1} \mathrm{H}-\mathrm{NMR}\left(300 \mathrm{MHz}, \mathrm{CDCl}_{3}+\mathrm{D}_{2} \mathrm{O}\right) \delta$ : 0.07 and $0.15\left(2 \mathrm{~s}, 6 \mathrm{H}, 2 \mathrm{CH}_{3}\right), 0.79(\mathrm{~s}, 9 \mathrm{H}, t-$ But), 1.26 (d, 3H, $\mathrm{CH}_{3}$ isopropyl, $\left.J=7.0 \mathrm{~Hz}\right), 1.28$ (d, 3H, $\mathrm{CH}_{3}$ isopropyl, $\left.J=7.0 \mathrm{~Hz}\right), 1.33$ (d, $3 \mathrm{H}, \mathrm{CH}_{3}$ isopropyl, $J=6.6 \mathrm{~Hz}), 1.35\left(\mathrm{~d}, 3 \mathrm{H}, \mathrm{CH}_{3}\right.$ isopropyl, $\left.J=6.6 \mathrm{~Hz}\right), 1.92\left(\mathrm{~s}, 3 \mathrm{H}, \mathrm{CH}_{3}-5\right), 2.87-3.05(\mathrm{~m}, 3 \mathrm{H}$, 2H-5' and $\mathrm{CH}$ isopropyl), 3.16 (sextuplet, 1H, CH isopropyl), 4.58 (m, 1H, H-4'), 5.07 (d, 1H, H-2', $\left.J_{1^{\prime}, 2^{\prime}}=8.3 \mathrm{~Hz}\right), 5.17\left(\mathrm{~d}, 1 \mathrm{H}, \mathrm{H}-1^{\prime}, J_{1^{\prime}, 2^{\prime}}=8.3 \mathrm{~Hz}\right), 6.98(\mathrm{~s}, 1 \mathrm{H}, \mathrm{H}-6) .{ }^{13} \mathrm{C}-\mathrm{NMR}\left(100 \mathrm{MHz}, \mathrm{CDCl}_{3}+\right.$ $\left.\mathrm{D}_{2} \mathrm{O}\right)$ : : -5.5 $\left(\mathrm{CH}_{3}\right), 4.6\left(\mathrm{CH}_{3}\right), 12.0\left(\mathrm{CH}_{3}\right), 17.8(\mathrm{C}), 19.3\left(\mathrm{CH}_{3}\right), 19.6\left(\mathrm{CH}_{3}\right), 21.1\left(\mathrm{CH}_{3}\right), 21.4\left(\mathrm{CH}_{3}\right)$, 24,1 (CH), $25.4\left(\mathrm{CH}_{3}\right), 46.0\left(\mathrm{CH}_{2}\right), 49.9(\mathrm{CH}), 70.0(\mathrm{CH}), 81.8(\mathrm{CH}), 90.4(\mathrm{CH}), 96.8(\mathrm{CH}), 106.4(\mathrm{C}=)$, $112.3(\mathrm{C}-5), 141.1(\mathrm{C}-6), 150.8(\mathrm{CO}), 159.9(\mathrm{C}=), 162.3(\mathrm{CO}) . \mathrm{MS}\left(\mathrm{ESI}^{+}\right) \mathrm{m} / \mathrm{z}: 560.5\left[\mathrm{M}^{+} \mathrm{NH}_{4}\right]^{+}$ $(100 \%), 542.5[\mathrm{M}+\mathrm{H}]^{+}(85 \%)$. Anal. Calcd for $\mathrm{C}_{24} \mathrm{H}_{39} \mathrm{~N}_{3} \mathrm{O}_{7} \mathrm{SSi}$ : C, 53.21; H, 7.26; N, 7.76. Found: $\mathrm{C}$, 53.69; H, 7.16; N, 7.81. HPLC: $t_{R}=10.4$ min.TLC (Hexane / EtOAc, 1:2) Rf: 0.49 (heating).

5', $N^{4 "}$-Cyclo-[1-[2'-O-(tert-butyldimethylsilyl)-5'-deoxy- $\beta$-D-ribofuranosyl]thymine]-3'-spiro-5'”-

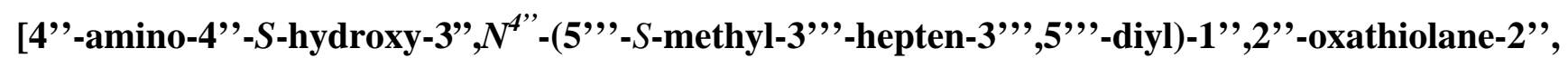
2''-dioxide] (22) and 5', $N^{4 \prime}$-Cyclo-[1-[2'-O-(tert-butyldimethylsilyl)-5'-deoxy- $\beta$-Dribofuranosyl]thymine]-3'-spiro-5"'-[4"'-amino-4"'-S-hydroxy-3", $N$ 4"'-(5'”- $R$-methyl-3'”'-hepten3"',5"'-diyl)- 1"',2"'-oxathiolane-2"', 2"'-dioxide] (23). A solution of nucleoside 3 (50 mg, $0.1 \mathrm{mmol}$ ) in 2-butanone $(2.5 \mathrm{~mL})$ and triethylamine $(0.05 \mathrm{~mL})$ was stirred at room temperature for $24 \mathrm{~h}$. Then, the solvent was evaporated under reduced pressure and the residue was purified by CCTLC using hexane/EtOAc, 3:1 as eluent. 
From the fastest moving band, $7.5 \mathrm{mg}$ of $22(14 \%)$ was isolated as a foam ${ }^{1} \mathrm{H}-\mathrm{NMR}$ (300 MHz, acetone- $\left.d_{6}\right) \delta: 0.09$ and $0.17\left(2 \mathrm{~s}, 6 \mathrm{H}, 2 \mathrm{CH}_{3}\right), 0.90\left(\mathrm{~s}, 9 \mathrm{H}, t\right.$-But), $1.09\left(\mathrm{t}, 3 \mathrm{H}, \mathrm{CH}_{3}\right), 1.10\left(\mathrm{~m}, 3 \mathrm{H}, \mathrm{CH}_{3}\right)$, $1.37\left(\mathrm{~s}, 3 \mathrm{H}, \mathrm{CH}_{3}\right), 1.74\left(\mathrm{~m}, 1 \mathrm{H}, \mathrm{CH}_{2} \mathrm{CH}_{3}\right), 1.81\left(\mathrm{~s}, 3 \mathrm{H}, \mathrm{CH}_{3}-5\right), 2.00\left(\mathrm{~m}, 1 \mathrm{H}, \mathrm{CH}_{2} \mathrm{CH}_{3}\right), 2.12(\mathrm{q}, 2 \mathrm{H}$, $\mathrm{CH}_{2} \mathrm{CH}_{3}$ ), 3.54 (s, 1H, H-3”), 3.64 (dd, 1H, H-5'a, $\left.J_{4^{\prime}, 5^{\prime} \mathrm{a}}=5.8 \mathrm{~Hz} ; J_{5^{\prime} a, 5^{\prime} b}=11.1 \mathrm{~Hz}\right), 3.82$ (d, 1H, H-5'b, $\left.J_{5^{\prime} a, 5^{\prime} b}=11.1 \mathrm{~Hz}\right), 4.48(\mathrm{~s}, 1 \mathrm{H}), 4.68\left(\mathrm{~d}, 1 \mathrm{H}, \mathrm{H}^{\prime} 4^{\prime}, J_{4^{\prime}, 5^{\prime} a}=5.8 \mathrm{~Hz}\right), 5.06\left(\mathrm{~d}, 1 \mathrm{H}, \mathrm{H}-2^{\prime}, J_{1^{\prime}, 2^{\prime}}=5.4 \mathrm{~Hz}\right)$ $5.81(\mathrm{~s}, 1 \mathrm{H}, \mathrm{OH}), 5.98\left(\mathrm{~d}, 1 \mathrm{H}, \mathrm{H}-1^{\prime}, J_{1^{\prime}, 2^{\prime}}=5.4 \mathrm{~Hz}\right), 7.64(\mathrm{~s}, 1 \mathrm{H}, \mathrm{H}-6), 10.26(\mathrm{br} \mathrm{s}, 1 \mathrm{H}, \mathrm{NH}) \cdot{ }^{13} \mathrm{C}-\mathrm{NMR}$ (125 MHz, acetone- $\left.d_{6}\right) \delta:-5.3\left(\mathrm{CH}_{3}\right),-4.5\left(\mathrm{CH}_{3}\right), 7.9\left(\mathrm{CH}_{3}\right), 12.1\left(\mathrm{CH}_{3}\right), 18.6(\mathrm{C}), 21.7\left(\mathrm{CH}_{3}\right), 25.8$ $\left(\mathrm{CH}_{3}\right), 27.2\left(\mathrm{CH}_{3}\right), 34.7(\mathrm{C}), 35.1\left(\mathrm{CH}_{2}\right), 49.6\left(\mathrm{CH}_{2}\right), 53.0\left(\mathrm{CH}_{2}\right), 63.9(\mathrm{CH}), 72.9(\mathrm{CH}), 81.9(\mathrm{CH}), 91.6$ (CH), $93.1(\mathrm{C}), 94.5(\mathrm{C}), 105.6(\mathrm{C}=), 112.2(\mathrm{C}-5), 136.8(\mathrm{C}=), 140.4(\mathrm{C}-6), 151.4(\mathrm{CO}), 163.6(\mathrm{CO})$. MS $\left(\mathrm{ESI}^{+}\right) \mathrm{m} / \mathrm{z}:[\mathrm{M}+\mathrm{H}]^{+}$584.7. Anal. Calcd for $\mathrm{C}_{26} \mathrm{H}_{41} \mathrm{~N}_{3} \mathrm{O}_{8} \mathrm{SSi}$ : C, 53.49; H, 7.08; N, 7.20. Found: $\mathrm{C}$, 53.59; H, 7.05; N, 7.21. TLC (hexane / EtOAc, 2:1) Rf: 0.59 (heating).

From the intermediate band, $7.6 \mathrm{mg}$ of $23(14 \%)$ was isolated as a foam. ${ }^{1} \mathrm{H}-\mathrm{NMR}(300 \mathrm{MHz}$, acetone- $\left.d_{6}\right) \delta: 0.09$ and $0.17\left(2 \mathrm{~s}, 6 \mathrm{H}, 2 \mathrm{CH}_{3}\right), 0.91(\mathrm{~s}, 9 \mathrm{H}, t-\mathrm{But}), 0.92\left(\mathrm{~m}, 3 \mathrm{H}, \mathrm{CH}_{3}\right), 1.02\left(\mathrm{dt}, 6 \mathrm{H}, \mathrm{CH}_{3}\right)$, 1.32 (s, 3H, $\mathrm{CH}_{3}$ ), 1.62 (dd, 1H, $\mathrm{CH}_{2} \mathrm{CH}_{3}$ ), 1.80 (s, 3H, $\left.\mathrm{CH}_{3}-5\right), 1.90$ (m, $1 \mathrm{H}, \mathrm{CH}_{2} \mathrm{CH}_{3}$ ), 2.12 (q, $2 \mathrm{H}$, $\mathrm{CH}_{2} \mathrm{CH}_{3}$ ), 3.52 (s, 1H, H-3”), 3.63 (dd, 1H, H-5'a, $\left.J_{4^{\prime}, 5^{\prime} a}=5.8 \mathrm{~Hz} ; J_{5}{ }^{\prime}, 5^{\prime} b=11.1 \mathrm{~Hz}\right), 3.83$ (d, 1H, H$\left.5^{\prime} \mathrm{b}, J_{5^{\prime}, 5^{\prime} b}=11.1 \mathrm{~Hz}\right), 4.52(\mathrm{~s}, 1 \mathrm{H}), 4.66\left(\mathrm{~d}, 1 \mathrm{H}, \mathrm{H}-4^{\prime}, J_{4^{\prime}, 5^{\prime} a}=5.8 \mathrm{~Hz}\right), 5.02\left(\mathrm{~d}, 1 \mathrm{H}, \mathrm{H}-2^{\prime}, J_{1^{\prime}, 2^{\prime}}=5.4\right.$ $\mathrm{Hz}), 5.80(\mathrm{~s}, 1 \mathrm{H}, \mathrm{OH}), 5.96\left(\mathrm{~d}, 1 \mathrm{H}, \mathrm{H}-1^{\prime}, J_{1^{\prime}, 2^{\prime}}=5.4 \mathrm{~Hz}\right), 7.64(\mathrm{~s}, 1 \mathrm{H}, \mathrm{H}-6), 10.23(\mathrm{br} \mathrm{s}, 1 \mathrm{H}, \mathrm{NH}) .{ }^{13} \mathrm{C}-$ NMR (125 MHz, acetone- $\left.d_{6}\right) \delta:-5.3\left(\mathrm{CH}_{3}\right),-4.5\left(\mathrm{CH}_{3}\right), 8.9\left(\mathrm{CH}_{3}\right), 12.6\left(\mathrm{CH}_{3}\right), 18.9(\mathrm{C}), 26.0\left(\mathrm{CH}_{3}\right)$, 27.1 $\left(\mathrm{CH}_{3}\right), 31.7(\mathrm{C}), 35.6\left(\mathrm{CH}_{2}\right), 49.8\left(\mathrm{CH}_{2}\right), 52.7\left(\mathrm{CH}_{2}\right), 63.9(\mathrm{CH}), 72.9(\mathrm{CH}), 81.9(\mathrm{CH}), 92.1(\mathrm{CH})$, 93.2 (C), 94.5 (C), 104.1 (C=), 112.2 (C-5), 137.0 (C=), 140.5 (C-6), $151.4(\mathrm{CO}), 163.8$ (CO). MS $\left(\mathrm{ESI}^{+}\right) \mathrm{m} / \mathrm{z}: \mathrm{MS}\left(\mathrm{ESI}^{+}\right) \mathrm{m} / \mathrm{z}:[\mathrm{M}+\mathrm{H}]^{+}$584.7 . Anal. Calcd for $\mathrm{C}_{26} \mathrm{H}_{41} \mathrm{~N}_{3} \mathrm{O}_{8} \mathrm{SSi}$ C, $53.49 ; \mathrm{H}, 7.08 ; \mathrm{N}, 7.20$ Found: C, 53.59; H, 7.05; N, 7.21. TLC (hexane / EtOAc, 2:1) Rf: 0.57 (heating).

From the slowest moving band, $7.5 \mathrm{mg}$ of $\mathbf{4}^{4}(16 \%)$ was isolated as a foam. 
5', $N^{4 "}$-Cyclo-[1-[2'-O-(tert-butyldimethylsilyl)-5'-deoxy- $\beta$-D-ribofuranosyl]thymine]-3'-spiro-5’'-

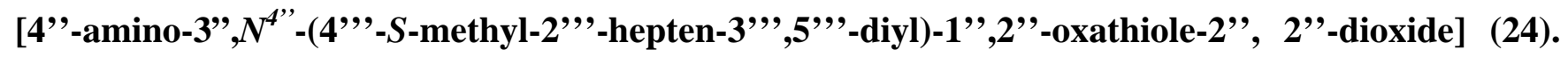

A solution of nucleoside $3\left(50 \mathrm{mg}\right.$, xxx mmol) in 3-pentanone (xxx mL) was stirred at $\mathrm{xxx}^{\circ} \mathrm{C}$ for $24 \mathrm{~h}$.

Then, the solvent was evaporated under reduced pressure and the residue was purified by CCTLC using hexane/EtOAc, 1:1 as eluent to afford 24 (xxx mg, $30 \%)$ as a white foam. ${ }^{1} \mathrm{H}-\mathrm{NMR}(300 \mathrm{MHz}$, acetone-

$d_{6}{ }^{1} \mathrm{H}-\mathrm{NMR}\left(300 \mathrm{MHz}\right.$, acetone- $\left.d_{6}\right) \delta: 0.09$ and $0.17\left(2 \mathrm{~s}, 6 \mathrm{H}, 2 \mathrm{CH}_{3}\right), 0.81\left(\mathrm{~d}, 3 \mathrm{H}, \mathrm{CH}_{3}, J=1.9 \mathrm{~Hz}\right), 0.91$ (s, 9H, t-But), $0.92\left(\mathrm{t}, 3 \mathrm{H}, \mathrm{CH}_{3}\right), 0.96\left(\mathrm{t}, 3 \mathrm{H}, \mathrm{CH}_{3}\right), 0.98\left(\mathrm{~m}, 3 \mathrm{H}, \mathrm{CH}_{3}\right), 1.47,1.51\left(\mathrm{~m}, 4 \mathrm{H}, 2 \mathrm{CH}_{2}\right), 1.88$ $\left(\mathrm{s}, 3 \mathrm{H}, \mathrm{CH}_{3}\right), 1.89$ (d, 3H, $\left.\mathrm{CH}_{3}, J=7.8 \mathrm{~Hz}\right), 2.29$ (q, 1H, CH), 4.24 (dd, 1H, H-5'a, J $4^{\prime}, 5^{\prime} a=8.8 \mathrm{~Hz} ; J_{5}{ }^{\prime} a, 5^{\prime} b$ $=10.5 \mathrm{~Hz}), 4.32\left(\mathrm{dd}, 1 \mathrm{H}, \mathrm{H}-5^{\prime}{ }^{\prime} \mathrm{b}, J_{4}{ }^{\prime}, 5^{\prime} b^{\prime}=6.1 \mathrm{~Hz}, J_{5}{ }^{\prime}, 5^{\prime} b=10.5 \mathrm{~Hz}\right), 5.13\left(\mathrm{dd}, 1 \mathrm{H}, \mathrm{H}-4^{\prime}, J_{4^{\prime}, 5^{\prime} a}=6.1 \mathrm{~Hz}\right.$ $\left.J_{5^{\prime} a, 5^{\prime} b}=8.8 \mathrm{~Hz}\right), 5.41\left(\mathrm{bs}, 1 \mathrm{H}, \mathrm{H}-2^{\prime}\right), 5.82\left(\mathrm{bs}, 1 \mathrm{H}, \mathrm{H}-2^{\prime}\right), 7.62(\mathrm{~s}, 1 \mathrm{H}, \mathrm{H}-6), 10.23$ (br s, $\left.1 \mathrm{H}, \mathrm{NH}\right) .{ }^{13} \mathrm{C}-$ NMR (125 MHz, acetone-d $\left.d_{6}\right) \delta:-3.3\left(\mathrm{CH}_{3}\right),-4.3\left(\mathrm{CH}_{3}\right), 8.4\left(\mathrm{CH}_{3}\right), 8.5\left(\mathrm{CH}_{3}\right), 12.8\left(\mathrm{CH}_{3}\right), 15.4\left(\mathrm{CH}_{3}\right)$, $16.1\left(\mathrm{CH}_{3}\right), 22.8\left(\mathrm{CH}_{2}\right), 26.8\left(\mathrm{CH}_{3}\right), 28.8\left(\mathrm{CH}_{2}\right), 40.2(\mathrm{CH}), 57.5\left(\mathrm{CH}_{2}\right), 65.6(\mathrm{C}), 73.9(\mathrm{CH}), 83.5(\mathrm{CH})$, $91.5(\mathrm{C}), 97.9(\mathrm{C}), 112.4(\mathrm{C}-5), 120.5(\mathrm{C}=), 123.9(\mathrm{C}=), 130.5(\mathrm{C}-6$ and $\mathrm{C}=), 151.9(\mathrm{CO}), 155.7(\mathrm{C}=)$, 164.5 (CO). $\mathrm{MS}\left(\mathrm{ESI}^{+}\right) \mathrm{m} / \mathrm{z}: \mathrm{MS}\left(\mathrm{ESI}^{+}\right) \mathrm{m} / \mathrm{z}:[\mathrm{M}+\mathrm{H}]^{+}$594.5. Anal. Calcd for $\mathrm{C}_{28} \mathrm{H}_{43} \mathrm{~N}_{3} \mathrm{O}_{7} \mathrm{SSi}$ : C, 56.63; H, 7.30; N, 7.08. Found: C, 56.59; H, 7.05; N, 7.21. TLC (hexane / EtOAc, 2:1) Rf: 0.57 (heating). COMPLETAR ERNESTO 


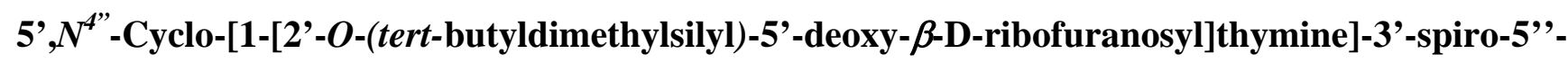

(4"'-methylcarbonylethylamino-4"'-S-hydroxy-1",2"'-oxathiolane-2",2"'-dioxide) (30). A solution

of hemiaminal $3(50 \mathrm{mg}, 0.1 \mathrm{mmol})$ and methyl vinyl ketone $(0.8 \mathrm{~mL}, 10 \mathrm{mmol})$ in dry acetonitrile $(2$ $\mathrm{mL}$ ) was stirred at room temperature for $24 \mathrm{~h}$. Then, the solvent was eliminated in vacuo and the resulting crude material was purified by CCTLC using dichloromethane/hexane, 6:4 as eluent until elimination of the unreacted methyl vinyl ketone, then using a polar gradient from dichloromethane $100 \%$ up to dichloromethane/MeOH 7:3, affording $32 \mathrm{mg}$ of $30(59 \%)$ as a white foam. ${ }^{1} \mathrm{H}-\mathrm{NMR}$ (400 MHz, benzene- $\left.d_{6}\right) \delta: 0.08$ and $0.30\left(2 \mathrm{~s}, 6 \mathrm{H}, 2 \mathrm{CH}_{3}\right), 1.00(\mathrm{~s}, 9 \mathrm{H}, t-\mathrm{But}), 1.40-1.50(\mathrm{~m}, 1 \mathrm{H}$, aqui debe estar el CHaN), 1.45 (s, 3H, CH CH $_{3}, 1.65-1.85$ (m, 2H), $1.80\left(\mathrm{~s}, 3 \mathrm{H}, \mathrm{CH}_{3}-5\right), 2.40$ (dd, $1 \mathrm{H}, \mathrm{H}-5$ 'b, $J=$ 10.8, $J=4.4 \mathrm{~Hz}), 2.50$ (m, 1H, CHbN), 2.60 (d, 1H, H-5'a, $J=10.8$ Hz), 2.88 (d, 1H, H-3”a, $J=13.8$ Hz), 2.89 (d, 1H, H-3’'b, J = 13.8 Hz), 4.10 (d, 1H, H-4', J = 4.2 Hz), 4.95 (d, 1H, H-2', J = 6.2Hz), 5.50 (s, $1 \mathrm{H}, \mathrm{OH}), 5.91$ (d, $1 \mathrm{H}, \mathrm{H}-1$ ', $J=6.2 \mathrm{~Hz}$ ), 6.62 (s, 1H, H-6), 8.83 (br s, $1 \mathrm{H}, \mathrm{NH}-\mathrm{Thy}$,). ${ }^{13} \mathrm{C}-$ NMR (100 MHz, benzene- $\left.d_{6}\right) \delta:-5.02\left(\mathrm{CH}_{3}\right),-4.6\left(\mathrm{CH}_{3}\right), 12.4\left(\mathrm{CH}_{3}\right), 18.3(\mathrm{C}), 25.8\left(\mathrm{CH}_{3}\right), 29.8\left(\mathrm{CH}_{3}\right)$, $40.0\left(\mathrm{CH}_{2}\right), 41.0\left(\mathrm{CH}_{2}\right), 50.8\left(\mathrm{CH}_{2}\right), 51.6\left(\mathrm{CH}_{2}\right), 72.9(\mathrm{CH}), 81.4(\mathrm{CH}), 92.2(\mathrm{CH}), 94.6(\mathrm{C}), 99.0(\mathrm{C})$,

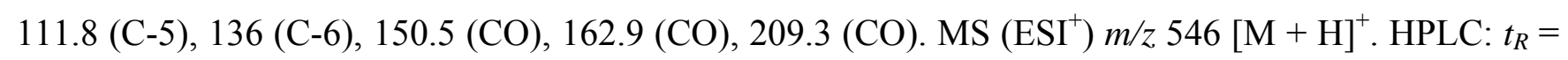
8.8 min. TLC $\left(\mathrm{CH}_{2} \mathrm{Cl}_{2}\right.$ / MeOH, 9:1) Rf: 0.33 (heating). Anal. Calcd for $\mathrm{C}_{22} \mathrm{H}_{35} \mathrm{~N}_{3} \mathrm{O}_{9} \mathrm{SSi}: \mathrm{C}, 48.42 ; \mathrm{H}$, 6.46; N, 7.70. Found: C, 48.76; H, 6.44; N, 7.76. Confirmar datos ERNESTO

(1R,3R,4R,5R)-4-(tert-Butyldimethylsilyloxy)-7-methylcarbonylethyl-5-mesyloxy-6-oxo-3-(thymin1'-yl)-7-aza-2-oxabicyclo[3.3.0]octane (31). Stability of 30 in different solvents was analysed by ${ }^{1} \mathrm{H}$ NMR and the results were summarised in Table 1. The ratio of $\mathbf{3 0}$ and $\mathbf{3 1}$ was determined from the values of their respective integrals.

In a non-polar aprotic solvent such as benzene- $d_{6}$, compound $\mathbf{3 0}$ was stable for days (entry 2 ). In a polar solvent as methanol- $d_{4}$, opening of the spiro sultone rind proceeded rapidly, within a few minutes (entry 5), while in less polar, aprotic solvents such as acetonitrile- $d_{3}$ and DMSO- $d_{6}$ (entries 3 and 4) 
quantitative opening requires hours. In acetone, opening was only partial and a mixture of $\mathbf{3 0}$ and $\mathbf{3 1}$ was obtained after 21 days.

To isolate $\mathbf{3 1}$ a solution of $\mathbf{3 0}$ in methanol was stirred for $15 \mathrm{~min}$. The deuterated solvent was eliminated in vacuo and the resulting crude material was purified by CCTLC using dichloromethane/hexane, 6:4 as eluent to give 31 as a foam. ${ }^{1} \mathrm{H}-\mathrm{NMR}\left(400 \mathrm{MHz}\right.$, acetonitrile- $\left.d_{3}\right) \delta$ : 0.02 and $0.20\left(2 \mathrm{~s}, 6 \mathrm{H}, 2 \mathrm{CH}_{3}\right), 0.80(\mathrm{~s}, 9 \mathrm{H}, t-\mathrm{But}), 1.90\left(\mathrm{~s}, 3 \mathrm{H}, \mathrm{CH}_{3}-5\right), 2.20\left(\mathrm{~s}, 3 \mathrm{H}, \mathrm{CH}_{3}\right), 2.80(\mathrm{t}, 2 \mathrm{H}$, $\left.\mathrm{CH}_{2} \mathrm{~N}, J=6.6 \mathrm{~Hz}\right), 3.20\left(\mathrm{~s}, 3 \mathrm{H}, \mathrm{CH}_{3} \mathrm{SO}_{2}\right), 3.40(\mathrm{dd}, 1 \mathrm{H}, \mathrm{H}-5$ 'a, $J=11.4 \mathrm{~Hz}, J=1.6 \mathrm{~Hz}), 3.40(\mathrm{~m}$, 1H,CHaCO), 3.60 (dt, 1H, CHbCO $J=14.0 \mathrm{~Hz}, J=7.2 \mathrm{~Hz}), 3.75$ (dd, 1H, H-5'a, $J=11.6 \mathrm{~Hz}, J=6.8$ Hz), 4.20 (d, 1H, H-2', J=8.0 Hz), 4.90 (dd, 1H, H-4', J=6.8 Hz, J=1.6 Hz ), 5.90 (d, 1H, H-1', J= $8.0 \mathrm{~Hz}), 7.30$ (s, 1H, H-6), 9.10 (br s, 1H, NH-Thy,). ${ }^{13} \mathrm{C}-\mathrm{NMR}$ (100 MHz, acetonitrile- $\left.d_{3}\right) \delta: \quad-5.4$ $\left(\mathrm{CH}_{3}\right),-4.4\left(\mathrm{CH}_{3}\right), 12.2\left(\mathrm{CH}_{3}\right), 18.4(\mathrm{C}), 25.7\left(\mathrm{CH}_{3}\right), 30.1\left(\mathrm{CH}_{3}\right), 38.9\left(\mathrm{CH}_{2}\right), 40.4\left(\mathrm{CH}_{2}\right), 41.5\left(\mathrm{CH}_{3}\right)$, $51.4\left(\mathrm{CH}_{2}\right), 77(\mathrm{CH}), 78.9(\mathrm{CH}), 87.6(\mathrm{CH}), 88.3(\mathrm{C}), 112.6(\mathrm{C}-5), 135.8(\mathrm{C}-6), 151.5(\mathrm{CO}), 163.9(\mathrm{CO})$, $168.2(\mathrm{CO}), 208.2(\mathrm{CO}) . \mathrm{MS}\left(\mathrm{ESI}^{+}\right) \mathrm{m} / \mathrm{z} 546[\mathrm{M}+\mathrm{H}]^{+} . \mathrm{HPLC}: t_{R}=8.8 \mathrm{~min} . \mathrm{TLC}\left(\mathrm{CH}_{2} \mathrm{Cl} / \mathrm{MeOH}, 9: 1\right)$ Rf: 0.33 (heating). Anal. Calcd for $\mathrm{C}_{22} \mathrm{H}_{35} \mathrm{~N}_{3} \mathrm{O}_{9} \mathrm{SSi}$ : C, 48.42; H, 6.46; N, 7.70. Found: C, 48.51; H, $6.56 ; \mathrm{N}, 7.69$.

TABLE 1. Transformation that experiment 30 in different deuterated solvents. 


\begin{tabular}{|c|c|c|c|c|}
\hline Entry & Solvent & Time & $30(\%)$ & $31(\%)$ \\
\hline \multirow{7}{*}{1} & \multirow{7}{*}{ Acetone- $\mathrm{d}_{6}$} & $15 \mathrm{~min}$ & 95 & 5 \\
\hline & & $30 \mathrm{~min}$ & 90 & 10 \\
\hline & & $24 \mathrm{~h}$ & 45 & 55 \\
\hline & & $48 \mathrm{~h}$ & 40 & 60 \\
\hline & & 7 days & 35 & 65 \\
\hline & & 14 days & 75 & 25 \\
\hline & & 21 days & 75 & 25 \\
\hline \multirow{5}{*}{2} & \multirow{5}{*}{ Benzene- $d_{6}$} & $15 \mathrm{~min}$ & 100 & - \\
\hline & & $30 \mathrm{~min}$ & 100 & - \\
\hline & & 16 & 100 & - \\
\hline & & 1 day $h$ & 100 & - \\
\hline & & $>3$ days & 95 & 5 \\
\hline 3 & Acetonitrile- $\mathrm{d}_{3}$ & $<8 \mathrm{~h}$ & - & 100 \\
\hline 4 & DMSO- $\mathrm{d}_{6}$ & $<6 \mathrm{~h}$ & - & 100 \\
\hline 5 & Methanol-d $\mathrm{d}_{4}$ & $\begin{array}{l}<15 \\
\min \end{array}$ & - & 100 \\
\hline
\end{tabular}

Acknowledgment. We thank Susana Ruiz for excellent technical assistance. The Spanish Ministerio de Educación y Ciencia, MEC (project ref: SAF 2006-12713-C02-01) is also acknowledged for financial support. The Spanish Consejo Superior de Investigaciones Científicas is also acknowledged for a JAE-Doc contract of the Program "Junta para la Ampliación de Estudios" to M.-C. B. 
Supporting Information Available. General experimental methods, NMR procedures, and copies of spectra for $3,5,6,7,19,21,22,23,24,30$ and 31 . In addition, gHSQC of the reaction of 3 with acetone after $7 \mathrm{~h}$ is available. This material is available free of charge via the Internet at http://pubs.acs.org.

\section{References}

(1) Tietze, L F. Chem. Rev. 1996, 96, 115-136.

(2) (a) Tietze, L. F.; Beifuss, U. Angew. Chem. Int. Ed. Engl. 1993, 32, 131-312. (b) Ho. T.-I. Tandem Reactions in Organic Synthesis, Wiley: New York, 1992.

(3) Chamorro, C.; Luengo, S. M.; Bonache, M. C.; Velázquez, S; Pérez-Pérez, M. J.; Camarasa, M. J.; Gago, F.; Jimeno, M. L.; San-Félix, A. J. Org. Chem. 2003, 68, 6695-6704.

(4) Bonache, M. C.; Chamorro, C.; Cordeiro, A.; Camarasa, M. J.; Jimeno, M. L.; San-Félix A. J. Org. Chem. 2004, 69, 8758-8766.

(5) Hurd, R.E.; John, B.K. J. Magn. Reson. 1991, 91, 648-653.

(6) Kay, L.E.; Keifer P.; Saarinen, T. J. Am. Chem. Soc. 1992, 114, 10663-10665.

(7) (a) Stork, G; Terrell, R. and Szmuszkovicz J. J. Am. Chem. Soc. 1954, 76, 2029-2030. (b) Stork G.; Brizzolara A.; Landesman H..; Szmuszkovicz J. and Terrell, R. J. Am. Chem. Soc. 1963, 85, $207-$ 222.

(8) Mukherjee, S; Yang J. W; Hoffmann S. and List, B. Chem. Rev. 2007, 107, 5471-5569.

(9) For recent reviews see: (a) Anniina E.; Inkeri M. and Petri M. P. Chem. Rev. 2007, 107, 5416-5470. (b) List, B. Acc. Chem. Res. 2004, 37, 548-557. (c) List, B. Tetrahedron 2002, 58, 5573-5590. 
(10) (a) List, B. J. Am. Chem. Soc. 2000, 122, 9336-9337. (b) List, B.; Pojarliev, P.; Biller, W.T.; Martin, H. J. J. Am. Chem. Soc. 2002, 124, 827-833. (c) Notz, W.; Sakthivel, K.; Bui, T.; Zhong, G.; Barbas III, C. F. Tetrahedron Lett. 2001, 42, 199-201.

(11) (a) List, B.; Pojarliev, P.; Martin, H. J. Org. Lett. 2001, 3, 2423-2425. (b) Enders, D.; Seki, A. Synlett 2002, 25-28. (c) Betancort, J. M.; Sakthivel, K.; Thayumanavan, R.; Barbas III, C. F.; Tetrahedron Lett 2001, 42, 4441-4444. (d) Alexakis, A.; Andrey, O. Org. Lett, 2002, 4, 3611-3614. (e) Yamaguchi, M.; Yokota, N.; Minami, T. J. Chem. Soc. Chem. Commun. 1991, 1088-1089.

(12) (a) Sakthivel, K.; Notz, W.; Bui, T.; Barbas III, C. F. J. Am. Chem. Soc. 2001, 123, 5260-5267. (b) List, B.; Lerner, R. A.; Barbas III, C. F. J. Am. Chem. Soc. 2000, 122, 2395-2396. (c) Notz, W.; List, B. J. Am. Chem. Soc. 2000, 122, 7386-7387. (d) Martin, H. J.; List, B. Synlett 2003, 1901-1902. (e) Puchot, C.; Samuel, O.; Dunach, E.; Zhao, S.; Agami, C.; Kagan, H. B. J. Am. Chem. Soc. 1986, 108, 2325-2357. (f) List, B.; Pojaraliev, P.; Castello, C. Org. Lett. 2001, 3, 573-575. (g) Hoang, L.; Bahmanyar, S.; Houk, K. N.; List, B. J. Am. Chem. Soc. 2003, 125, 16-17. (h) Bahmanyar, S.; Houk, K. N. J. Am. Chem. Soc. 2001, 123, 11273-11283. (i) List, B. Acc. Chem. Res. 2004, 37, 548-557. (j) Marquez, C.; Metzger, J. O. Chem. Commun. 2006, 1539-1541.

(13) (a) Gryko, D.; Zimnicka, M.; Lipinski, R. J. Org. Chem. 2007, 72, 964-970. (b) Tang, Z.; Cun, L.F.; Cui, X.; Mi, A.-Q.; Jiang, Y.-Z.; Gong, L.-Z. Org. Lett. 2006, 8, 1263-1266. (c) Raj, M.; Vishnumaya; Ginotra, S. K.; Singh, V. K. Org. Lett. 2006, 8, 4097-4099. (d) Cheng, Ch.; Sun, J.; Wang, Ch.; Zhang, Y.; Wei, S.; Jiang, F.; Wu, Y. Chem Commun. 2006, 215-217. (e) Raj, M.; Wang, Ch.; Zhang, Y.; Wei, S.; Jiang, F.; Wu, Y. Chem Commun. 2006, 215-217. (e) Zhang, H.; Mitsumori, S; Utsumi, N.; Imai, M.; Garcia-Delgado, N.; Mifsud, M.; Albertshofer, K.; Cheong, P. Ha-Yeon; Houk, K. N.; Tanaka, F; Barbas III, C. F. J. Am. Chem. Soc. 2008, 130, 875-886.

(14) Saito, S.; Nakadai, M; Yamamoto, H. Synlett 2001, 1245-1248. (b) Mangion, I. K.; Northrup, A. B.; MacMillan, D. W. C. Angew. Chem. Int. Ed. 2004, 43, 6722-6724. (c) Chuanling, Ch.; Wei, S.; Sun, J. Synlett 2006, 2419-2422. 
(15) Pérez-Pérez, M. J; Balzarini, J.; Hosoya, M.; De Clercq, E.; Camarasa, M. J. Bioorganic and Med Chem Lett. 1992, 2, 647-648.

(16) IUPAC nomenclature home page. http://www.chem.qmul.ac.uk/iupac/ 